\title{
Stone Fruit as Biofactories of Phytochemicals With Potential Roles in Human Nutrition and Health
}

\author{
María Valeria Lara ${ }^{1 *}$, Claudio Bonghi ${ }^{2}$, Franco Famiani ${ }^{3}$, Giannina Vizzotto ${ }^{4}$, \\ Robert P. Walker ${ }^{3}$ and María Fabiana Drincovich ${ }^{1 *}$
}

1 Centro de Estudios Fotosintéticos y Bioquímicos, Consejo Nacional de Investigaciones Cientificas y Técnicas, Facultad de Ciencias Bioquímicas y Farmacéuticas, Universidad Nacional de Rosario, Rosario, Argentina, ${ }^{2}$ Department of Agronomy, Food, Natural Resources, Animals and Environment, University of Padova Agripolis, Legnaro, Italy, ${ }^{3}$ Dipartimento di Scienze Agrarie, Alimentari e Ambientali, Università degli Studi di Perugia, Perugia, Italy, ${ }^{4}$ Department of Agricultural, Food,

Environmental, and Animal Sciences, University of Udine, Udine, Italy

\section{OPEN ACCESS}

Edited by:

Angelos K. Kanellis,

Aristotle University of Thessaloniki,

Greece

Reviewed by:

loannis S. Minas,

Colorado State University,

United States

Clara Pons Puig,

Polytechnic University of Valencia,

Spain

*Correspondence:

María Valeria Lara

lara@cefobi-conicet.gov.ar

María Fabiana Drincovich

drincovich@cefobi-conicet.gov.ar

Specialty section:

This article was submitted to Plant Metabolism and Chemodiversity,

a section of the journal

Frontiers in Plant Science

Received: 14 May 2020

Accepted: 12 August 2020

Published: 02 September 2020

Citation:

Lara MV, Bonghi C, Famiani F, Vizzotto G, Walker RP and Drincovich MF (2020) Stone Fruit as

Biofactories of Phytochemicals With Potential Roles in

Human Nutrition and Health.

Front. Plant Sci. 11:562252. doi: 10.3389/fpls.2020.562252
Phytochemicals or secondary metabolites present in fruit are key components contributing to sensory attributes like aroma, taste, and color. In addition, these compounds improve human nutrition and health. Stone fruits are an important source of an array of secondary metabolites that may reduce the risk of different diseases. The first part of this review is dedicated to the description of the main secondary organic compounds found in plants which include (a) phenolic compounds, (b) terpenoids/ isoprenoids, and (c) nitrogen or sulfur containing compounds, and their principal biosynthetic pathways and their regulation in stone fruit. Then, the type and levels of bioactive compounds in different stone fruits of the Rosaceae family such as peach (Prunus persica), plum (P. domestica, $P$. salicina and $P$. cerasifera), sweet cherries ( $P$. avium), almond kernels ( $P$. dulcis, syn. $P$. amygdalus), and apricot ( $P$. armeniaca) are presented. The last part of this review encompasses pre- and postharvest treatments affecting the phytochemical composition in stone fruit. Appropriate management of these factors during pre- and postharvest handling, along with further characterization of phytochemicals and the regulation of their synthesis in different cultivars, could help to increase the levels of these compounds, leading to the future improvement of stone fruit not only to enhance organoleptic characteristics but also to benefit human health.

Keywords: chlorogenic acid, flavonoids, anthocyanins, carotenoids, postharvest, volatiles, health-promoting, cyanogenic compounds

\section{HEALTH PROMOTING PROPERTIES OF FRUIT PHYTOCHEMICALS}

Here, a brief description of the main secondary organic compounds found in plants, their principal biosynthetic pathways, and their biosynthesis regulation in stone fruit is provided. Then, a review about the levels and types of secondary metabolites found in different stone fruit is presented. The factors that have been identified as being involved in defining the levels of these compounds in stone fruit are finally presented. It is concluded that the identification of the key regulatory points in the 
biosynthesis of these compounds or in their chemical modification to produce more compounds with better activity, as well as the identification of pre- and postharvest managements that could increase their levels, will aid in the future improvement of stone fruit for the benefit of human health.

Phytochemicals known as secondary metabolites possess diverse physiological properties, being involved in sensory attributes (aroma, taste and color) and in defense against pathogens, different kind of stresses and/or injuries (TomasBarberan et al., 2001; Montevecchi et al., 2013). Besides, the secondary metabolites of plants are highly beneficial to consumers. In this regard, in recent decades, consumers have become more aware of the relationship between diet and diseases. Today, there is a broad consensus that increased consumption of fruits and vegetables contributes to improving health and well-being by reducing the risk of diseases, such as cardiovascular diseases and some forms of cancer (Riboli and Norat, 2003; Hung et al., 2004). The Joint FAO/WHO (Food and Agriculture Organization/World Health Organization) report on diet, nutrition, and prevention of chronic diseases recommended in 2003 the intake of a minimum $400 \mathrm{~g}$ of fruits and vegetables per day, ideally $800 \mathrm{~g}$, for the prevention of chronic diseases such as cancer, diabetes, heart disease and obesity (WHO Technical Report Series, 2003).

The health promoting properties of fruits and vegetables are due to the presence of some vitamins (such as A, C, E, and folates), dietary fibers, and secondary metabolites, some of which are unique of plants. Phenolic compounds, among which flavonoids are the most ingested during daily life from products of plant origin (Chun et al., 2007), are important secondary organic metabolites in terms of their health-promoting properties, with possible preventive role in neurological disorders and potential protection against chronic diseases (Weng and Yen, 2012; Silva and Poganik, 2020). In addition, different biological activities have been described for chlorogenic acid, a phenolic compound, which include antiinflammatory (Liang and Kitts, 2016), anticancer (Liu Y. J. et al., 2013), antioxidant power, including the inhibition of lipid oxidation (Sasaki et al., 2010), antilipidic, antiepileptic, neuroprotective (Aseervatham et al., 2016), antidiabetic (Meng et al., 2013), and antihypertensive (Suzuki et al., 2006; Zhao et al., 2012). This phenolic compound has also beneficial effects in disorders related to the metabolic syndrome (Bhandarkar et al., 2019a; Bhandarkar et al., 2019b). Moreover, it possesses antimicrobial activity against a wide range of organisms, including bacteria, yeasts, molds, viruses, and amoebas, and thus, it could be used as an antimicrobial agent (SantanaGálvez et al., 2017) for the preservation of food products. In addition, anthocyanins, another group of polyphenols, prevent tumor development by inhibiting cancer cells proliferation when tested in vitro and in vivo. Anthocyanins also exhibit anti-inflammatory activity, present neuroprotective, antiobesity, antidiabetic activities and are proposed to prevent cardiovascular disease (extensively reviewed in Li et al., 2017). With respect to caroteonids, their role in human nutrition is well established as precursors of vitamin $\mathrm{A}$ and due to their antioxidant activity. Their protective function in liver health is well documented and reviewed by Elvira-Torales et al. (2019). Other metabolites that have received attention are the cyanogenic glycosides, which possess anticancer properties (Fukuda et al., 2003, Jaswal et al., 2018).

Different studies have indicated that stone fruits are particularly rich in important phytochemicals, which constitute an extra benefit to their pleasant taste and flavor. These metabolites include phenolic compounds and terpenoids, among others. Peach, plums, cherries have an important antioxidant activity due to their phenolic content (Kim et al., 2003b; Cevallos-Casals et al., 2006; Serra et al., 2011). In vitro studies have demonstrated the antimicrobial activity of plum and peach extracts (Cevallos-Casals et al., 2006; Belhadj et al., 2016). In vitro and ex vivo studies also showed the antiinflammatory properties of $P$. persica extracts (Gasparotto et al., 2014). Pharmacological studies showed that $P$. persica has antihypertensive properties (Kim et al., 2019), and it influences the central cholinergic system (Kim et al., 2003c). Moreover, intake of peaches protects rat tissues from nicotine toxicity (Kim et al., 2017). Almond intake reduces cardiovascular disease risk by modulating plasma lipoproteins (extensively reviewed in Berryman et al., 2011), contributes to satiety (Hull et al., 2015), delays lipid bioaccessibility (reviewed in Grundy et al., 2016), and decreases inflammation and oxidative stress (reviewed in Kamil and Chen, 2012). Apricot has also an important therapeutic and nutritional value. Among its health promoting activities, antimicrobial, antimutagenic, cardioprotective, hepato-protective, and antioxidant properties have been described (Ozturk et al., 2009; Erdogan-Orhan and Kartal, 2011; Yurt and Celik, 2011; Chen et al., 2020).

\section{MAIN SECONDARY ORGANIC COMPOUNDS FOUND IN PLANTS: GENERAL DESCRIPTION OF THE BIOSYNTHETIC PATHWAYS AND REGULATION WITH EMPHASIS IN STONE FRUITS}

Secondary metabolites can be grouped into three major classes: (a) phenolic compounds, (b) terpenoids/isoprenoids, and (c) nitrogen or sulfur containing compounds. These phytochemicals are derived from main primary pathways (glycolysis, the tricarboxylic citric acid (TCA) cycle, the pentose phosphate pathway, aliphatic and aromatic amino acids and the shikimic acid pathway) (Figure 1) (Aharoni and Galili, 2011). The shikimate pathway is a key route that conducts the synthesis of tyrosine, phenylalanine, and tryptophane (for review, see Tzin and Galili, 2010; Vogt, 2010; Maeda and Dudareva, 2012). This synthetic route starting from phosphoenolpyruvate (PEP) and erythrose 4-phosphate (E4P) connects primary metabolism to aromatic amino acid biosynthesis. This pathway, together with its intermediate metabolites (i.e. chorismate), provides precursors for the biosynthesis of folates, quinones, phytohormones, 


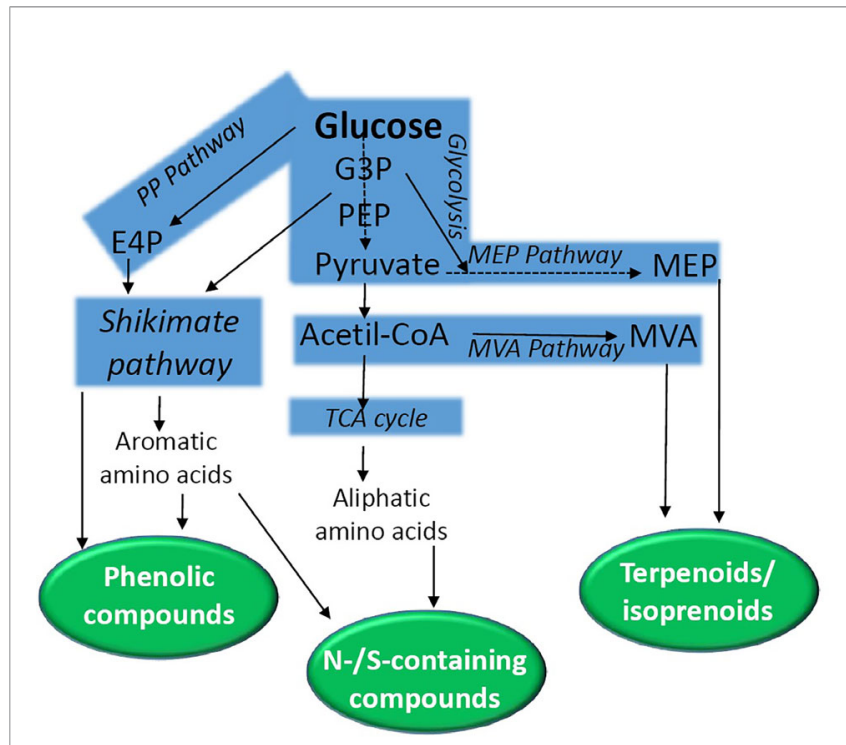

FIGURE 1 | A simplified scheme of the biochemical pathways conducting the synthesis of secondary metabolites in plants. Natural products are grouped into phenolic compounds, N-/S-containing compounds, and terpenoids. E4P, erythrose 4-phosphate; G3P, glyceraldehyde 3-phosphate; MEP, 2-C-methyl-d-erythritol 4-phosphate; MEV, mevalonate; PP, Pentose phosphate; PEP, phosphoenolpyruvate; TCA, tricarboxylic acid.

alkaloids, indole glucosinolates, flavonoids, hydroxycinnamic acids, lignins, and lignans.

\section{Phenolic Compounds}

Phenolic compounds are synthesized from shikimic/ phenylpropanoid and the phenylpropanoid-acetate-malonate pathways and encompass a large group of monomeric and polymeric phenols and polyphenols. Phenylalanine is the precursor of a wide range of volatiles including phenylpropenes, phenylpropanes, phenethyl derivatives, and benzenoids (Gonda et al., 2018).

Phenylpropanoids are simple phenolic compounds with a benzene ring and a lateral chain, which serve as precursors of compounds such as benzoic acid derivatives, flavonoids, coumarins, stilbenes, lignans and lignins, and condensed tannins (Oksana et al., 2012). The phenylpropanoid pathway initiates with phenylalanine synthesized in the shikimic acid pathway, which generates cinnamate by the action of phenylalanine ammonia lyase (PAL, Figure 2). The consecutive action of cinnamic acid 4-hydroxylase $(\mathrm{C} 4 \mathrm{H})$ renders 4-coumarate that finally gives 4 -coumaroyl-CoA by the action of 4-coumarateCoA ligase (4CL).

Phenolic acids include derivatives of benzoic acid $\left(\mathrm{C}_{6}-\mathrm{C}_{1}\right)$ such as hydroxybenzoic acids and of cinnamic acid (called hydroxycinnamic acids, $\mathrm{C}_{6}-\mathrm{C}_{3}$ ) (Walker and Famiani, 2018). The hydroxybenzoic acids 4-hydroxybenzoic acid (4-HBA), vanillic acid (3-methoxy-4-hydroxy) and protocatechuic acid (3,4-dihydroxy) are constituents of lignin (Pietta et al., 2003). On the other hand, gallic acid is present in hydrolysable and condensed tannins. Hydroxycinammic acids include caffeic $(3,4-$ dihydroxycinnamic acid), ferulic (4-hydroxy-3-methoxycinnamic acid), sinapic acids (3,5-dimethoxy-4-hydroxy) and $p$-coumaric (4-hydroxy) acid, and their conjugates, mainly as esters of quinic acid (chlorogenic acids).

\section{Chlorogenic Acid}

Chlorogenic acid (5-O-caffeoylquinic acid) is an ester of caffeic acid and (-)-quinic acid from the hydroxycinnamic acid family. It can be found in different foods and herbs (Santana-Gálvez et al., 2017; Walker and Famiani, 2018).

Early studies proposed the direct synthesis of this compound through transesterification from caffeoyl-CoA (synthesized from

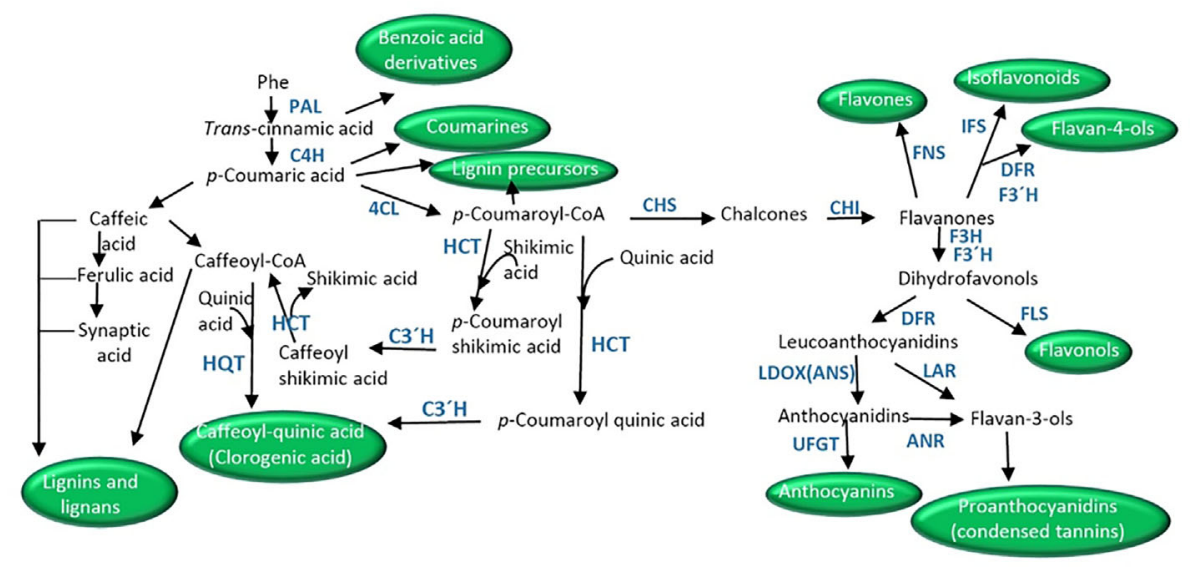

FIGURE 2 | Schematic of biosynthetic pathways derived from phenyalnaline leading to the synthesis of coumarins, benzoic acid derivatives, clorogenic acid, lignans, lignins, and the different flavonoids (isoflavonoids, flavonols, flavones, flavonls, anthocyanins, proanthocyanidins). ANR, anthocyanidin reductase; CHI, chalcone isomerase; $\mathrm{CHS}$, chalcone synthase; $\mathrm{C} 4 \mathrm{H}$, cinnamate-4-hydoxylase; $\mathrm{C} 3^{\prime} \mathrm{H}$, $p$-coumarate $3^{\prime}$-hydroxylase; $4 \mathrm{CL}, p$-coumaroyl CoA ligase; DRF, dihydroflavonol 4-reductase; F3H, flavanone 3-hydroxylase; FNS, flavone synthase; F3'H, flavonoid 3'-hydroxylase; FLS, flavonol synthase; HCT, hydroxycinnamoyl-CoA shikimate/ quinate hydroxycinnamoyl transferase; HQT, hydroxycinnamoyl-CoA quinate hydroxycinnamoyl transferase; IFS, isoflavone synthase; LDOX/ANS, leucoanthocyanidin dioxygenase/anthocyanidin synthase; LAR, leucoanthocyanidin reductase; PAL, phenylalanine ammonia lyase; UFGT, UDP-flavonoid glucosyl transferase. 
caffeic acid in the reaction catalyzed by $p$-coumarate 3-hydroxylase, $\mathrm{C} 3 \mathrm{H}$ ) and quinic acid by the action of hydroxycinnamoyl-CoA quinate hydroxycinnamoyl transferase (HQT, Stöckigt and Zenk, 1974, Figure 2). Nevertheless, the main route in higher plants is the 3 -hydroxylation of $p$-coumaroyl quinic acid by the cytochrome P450 monooxygenase $p$-coumarate $3^{\prime}$-hydroxylase or $p$-coumaroyl ester 3'-hydroxylase (C3'H, Niggeweg et al., 2004; Abdulrazzak et al., 2006; Figure 2). $p$-Coumaroyl quinic acid is synthesized from $p$-coumaroyl-CoA and quinic acid by the activities of a hydroxycinnamoyl-CoA shikimate/quinate hydroxycinnamoyl transferase (HCT). In addition, the action of $\mathrm{C}^{\prime} \mathrm{H}$ on $p$-coumaroyl shikimate (synthesized from $p$-coumaroyl-CoA and shikimate by HCT) to give caffeoyl shikimic, which then by the action of HCT (Hoffmann et al., 2003) gives shikimic acid and caffeoyl-CoA has also been described. Caffeoyl-CoA then is the substrate of HQT in the first reaction (Figure 2).

\section{Flavonoids}

Flavonoids consist of a fifteen-C phenylpropanoid core (the flavan skeleton) formed by two aromatic rings connected by a heterocyclic pyran ring $\left(\mathrm{C}_{6}-\mathrm{C}_{3}-\mathrm{C}_{6}\right)$. Depending on the oxidation and number of unsaturations of the pyran ring, flavonoids are classified into different groups named as flavones, flavanones, isoflavones, flavonols, 3-deoxy flavonoids, and anthocyanins (Andersen and Markham, 2005).

The general pathway of flavonoid synthesis branches from the phenylpropanoid and malonic pathways (Figures 1 and 2). The first committed step is catalyzed by the enzyme chalcone synthases (CHS) which synthesizes 4,2', $4^{\prime}, 6^{\prime}$-tetrahydroxychalcone (chalcone) by condensing $p$-coumaroyl-CoA with malonyl-CoA (Jez and Noel, 2000). Chalcones are the main precursors of all flavonoids (Dixon and Steele, 1999). The product of CHS is later isomerized into flavanones (e.g., naringenin or eriodictyol) by chalcone isomerase (CHI) (Winkel-Shirley, 2001). Flavanones are the precursors of flavones in the reaction catalyzed by flavone synthase (FNS) (Martens and Mithofer, 2005). Alternatively, flavanones give rise to dihydroflavonols (dihydrokaempferol), precursors of anthocyanins and proanthocyanidins, by the action of flavanone 3-hydroxylase $(\mathrm{F} 3 \mathrm{H})$. Dihydroflavanols can be routed to flavonols' synthesis by the action of flavonol synthase (FLS) (Pelletier et al., 1997). On the other hand, the action of flavonoid $3^{\prime}$-hydroxylase $\left(\mathrm{F} 3^{\prime} \mathrm{H}\right)$ or flavonoid $3^{\prime} 5^{\prime}$-hydroxylase $\left(\mathrm{F}^{\prime} 5^{\prime} \mathrm{H}\right)$ transforms dihydrokaempferol into dihydroquercetin or dihydromyricetin, respectively.

The existence of large number of flavonoids is the consequence of the different modifications on the main compounds by the action of different glycosyltransferases, methyltransferases, and acyltransferases (Saito et al., 2013). Flavonoid aglycones can be glycosylated at positions C-3, C-5, and C-7. The ability to glycosylate flavonol, anthocyanidin, and anthocyanin aglycones depends on the type of glycosyltransferase (Saito et al., 2013). Instead, flavonoid methyltransferases (FMTs) methylate flavonols giving isorhamnetin (Tohge et al., 2007).

Enzymes of the flavonoid biosynthetic pathway are grouped forming metabolons channelizing the different intermediates into the different routes (Winkel-Shirley, 1999). Although being cytosolic, the enzymes of the flavonoid pathway are bound to the cytoplasmic face of the endoplasmic reticulum by interacting with cytochrome $\mathrm{P} 450$ proteins (Saslowsky and Winkel, 2001). In addition, enzymes of the pathway such as CHS, CHI (Saslowsky et al., 2005), and FLS (Kuhn et al., 2011) have also been found in the nucleus.

\section{Anthocyanins}

Anthocyanins are water-soluble pigments belonging to the flavonoids and one of the main compounds responsible for coloration in plants (Tanaka et al., 2008). Their accumulation in the vacuole gives red, orange, blue, and purple color to different plant tissues and organs (Grotewold, 2006). Fruit color is a key quality trait, in which anthocyanin accumulation is involved.

Anthocyanins are synthesized as part of the flavonoid pathway through the action of dihydroflavonol 4-reductase (DFR, Heller et al., 1985; Reddy et al., 1987, Figure 2). The enzyme converts the dihydroflavonols or eriodictyol, a flavanone, to leucoanthocyanidins. The next step is catalysis by the action of a leucoanthocyanidin dioxygenase/anthocyanidin synthase (LDOX/ ANS) which finally gives the anthocyanidins (Nakajima et al., 2001). A great number of anthocyanidins have been described in plants, of which delphinidin, pelargonidin, cyaniding, and luteolinidin are the most abundant. Anthocyanidins are the precursors of 2,3-cis-2R,3R-flavan 3-ols (known as proanthocyanidins or condensed tannins; i.e. epicatechin) by the reaction catalyzed by anthocyanidin reductase (ANR, Xie et al., 2003). Condensed tannins contribute to the astringent flavor of fruits. Leucocyandins can conduct the synthesis of catechin, another proanthocyanidin, by the action of leucoanthocyanidin reductase (LAR). Chatechins are the units of the polymeric proanthocyanidins constituting a subgroup of flavonoids. Chatechins can be galloylated by esterification with gallate in the 3-position of the C-ring ( $\mathrm{He}$ et al., 2009). Alternatively, anthocyanidins can be modified by glycosylation to yield different anthocyanins (Figure 2). UDP-flavonoid glucosyl transferases (UFGT) catalyze the glycosylation of flavonoids using a UDPsugar at 3-, 5-, 7-, 3'-, or 4'-OH positions (Tohge et al., 2005; Bowles et al., 2006; Pang et al., 2008; Yonekura-Sakakibara et al., 2009; Montefiori et al., 2011). In addition, acylation and methylation also increase anthocyanin variability (Nakayama et al., 2003; Matsuba et al., 2010; Miyahara et al., 2012; Miyahara et al., 2013). Anthocyanin modification increases anthocyanin stability and water solubility due to intramolecular and/or intermolecular stacking (Springob et al., 2003).

Anthocyanin synthesis occurs in the cytosol through the flavonoid biosynthetic enzymes associated with the cytoplasmic face of the endoplasmic reticulum (Winkel-Shirley, 1999). Once formed, anthocyanins are stored in the vacuole to prevent oxidation (Marrs et al., 1995). Glutathione S-transferases (GSTs), transporters, and vesicles are involved in their transport into the vacuole (Grotewold, 2004). Depending on the species, anthocyanins are found uniformly distributed inside the vacuole or accumulated in discrete sub-vacuolar structures (Grotewold and Davis, 2008) anthocyanoplasts, intravacuolar pigmented globules' (cyanoplasts, Nozue et al., 1993) or anthocyanic vacuolar inclusions (Markham et al., 2000). 
The anthocyanin biosynthetic pathway is transcriptionally controlled by MYB and basic helix-loop-helix (bHLH) transcription factors, together with the WD40 proteins characterized by seven regions of 40 amino acids rich in tryptophan and aspartic acid (Quattrocchio et al., 1999; Hernandez et al., 2004). The ternary complex regulates the steps of the pathway in a spatial and temporal way during plant development (Hichri et al., 2011), and it is called MBW complex (Gonzales et al., 2008). bHLH and WD40 act as coactivators of MYBs, which may repress or activate anthocyanin biosynthetic genes (Koes et al., 2005; Dubos et al., 2008). bHLH proteins are essential to enhance the MYB-induced anthocyanin synthesis. NAC proteins are also involved in the regulation of anthocyanin synthesis in Arabidopsis (Morishita et al., 2009). Different factors such as light, temperature, and hormones modulate anthocyanin synthesis (Jeong et al., 2004; Takos et al., 2006; Steyn et al., 2009; Zhang et al., 2012). Anthocyanin biosynthesis is also developmentally controlled as demonstrated by the variation of promoter methylation of $M d M Y B 10$, the master regulator of the anthocyanin pathway in apple (ElSharkawy et al., 2015).

Studies about the regulation of the biosynthesis of some secondary compounds have been started to emerge in the Rosaceae family (Lin-Wang et al., 2010). In Japanese plum (Prunus salicina), RNA seq analysis allowed the identification of genes involved in anthocyanin synthesis. In the late stages of fruit maturation, when anthocyanin content increases, the expression of several genes, such as PsPAL, PsC4H, Ps4CL, PsCHS, PsCHI, PsF3H, $P s F 3^{\prime} H$, PsDFR, PsANS/LDOX, PsUFGT, and PsGST, is increased. Fang et al. (2016) found that MYBs expression correlated with structural genes. While c39005.graph_c0 (homologous to AtMYB113) positively correlated with anthocyanin biosynthetic genes, c29499.graph_c0 (homologous to AtMYB73) and c32850.graph_c0 (homologous to AtMYB102) showed a negative correlation. With respect to bHLH transcription factors, 36695.graph_c0 (homologous to AtTT8) positively correlated with anthocyanin contents, and 33382.graph_c0 (homologous to AtbHLH14) decreased with ripening. In addition, a gene encoding a NAC (c27539.graph_c0, AtNAC100) was also upregulated and positively correlated with the expression of genes involved in anthocyanin synthesis (Fang et al., 2016).

In prunus, levels of anthocyanins are responsible for the color and vary depending on the genotype, external factors, and organs. Moreover, Cheng et al. (2015) revealed that PsPAL, PsCHS, PsCHI, PsF3H, PsDFR, PsLDOX, and PsUFGT are up-regulated by ethylene treatment and repressed by 1-MCP. They showed that PsMYB10 is involved in this regulation. More recently, Niu et al. (2017) demonstrated that at high temperatures, anthocyanin levels are regulated not only by the synthesis but also by their degradation. Furthermore, they showed that hydrogen peroxide triggers anthocyanin enzymatic degradation via catalysis by a vacuolar peroxidase. Furthermore, Cheng et al. (2014) showed the expression of PpUGT78A1, PpUGT78A2, PpUGT78B, and PpUGT79B, encoding flavonoid 3-O-glycosyltransferase, varies among tissues and development, conducting the different patterns of anthocyanin accumulation.
Different studies were conducted to get insight into anthocyanin level regulation exploring the eventual redundancy of TFs during peach ripening (Lin-Wang et al., 2010; Ravaglia et al., 2013; Rahim et al., 2014). Analysis of MYB10 sequences reveals that R2R3 sequences from Rosaceae are highly conserved (Lin-Wang et al., 2010). Of the six MYB10s detected in peach genome (Verde et al., 2013) only PpMYB10.1-3 is expressed in the fruit (Rahim et al., 2014). Transient luciferase assays in Nicotiana benthamiana probed that PpMYB10.2 from peach (as well as those from pear, European plum, cherry-plum, cherry and apricot, denominated PcMYB10, PdmMYB10, PcfMYB10, PavMYB10, ParMYB10, and PprMYB10, respectively) induced anthocyanin synthesis activating Arabidopsis DFR-promoter when co-expressed with a bHLH (Lin-Wang et al., 2010). In addition, in the presence of bHLH, PpMYB10.2 also transactivated a reporter gene driven by a peach UFGT promoter (Ravaglia et al., 2013). PpMYB10.1 and PpMYB10.3 were shown to correlate with anthocyanin content in the peel, mesocarp, and mesocarp around the stone of peach fruit and with anthocyanin structural genes CHS, F3H, DFR and UFGT (Rahim et al., 2014). According to Tuan et al. (2015) PPMYB10.1 is a key factor regulating anthocyanin levels in redskinned peach (Japanese peach cultivar 'Akatsuki') and that it activates PpUFGT transcription. They proposed that $P p M Y B 10.2 /$ 3 could have a different role than pigment regulation since in 'Mochizuki' and 'Akatsuki' cultivars the transcript levels of PpMYB10.2 and -3 do not correlate with anthocyanin accumulation. Moreover, PpMYB10.2 was expressed in leaves that do not exhibit anthocyanin accumulation. In addition, Zhou et al. (2014) also indicated that PpMYB10.2 is not involved in anthocyanin synthesis in leaves. On the other hand, PpMYB10.4 is expressed in leaves, and it controls anthocyanin accumulation in this organ. PpMYB10.4 is mapped within the interval of the red allele that controls peach leaf color (Zhou et al., 2014). Studies in flowers reveal that $P$ PMYB9, is an activator highly expressed in peach flowers and it regulates UFGT gene expression. In the presence of PpbHLH3, PpMYB9 is able to induce anthocyanin synthesis when expressed in tobacco leaves. It is proposed that the PpMYB9 genes have diverged in functions from the MYB10 genes (Zhou et al., 2016). PpMYB17-20 are repressors, which levels varied during the different stages of flower development (Zhou et al., 2016).

Among three different bHLH candidate genes (based on homology with Arabidopsis), PpbHLH3 allowed the induction of the pigments when $P p M Y B 10.1$ or $P p M Y B 10.3$ were expressed in tobacco. Analysis of the genome reveals that $P$ PMYB10.1-3 are located within $80 \mathrm{~kb}$ on pseudomolecule 3 , within the two closest markers (CC2 and $\mathrm{CC} 12 \mathrm{~A}$ ) to the anther color trait, and thus highlighting the role of these transcription factors in the anthocyanin synthesis regulation (Rahim et al., 2014). On the other hand, Zhou et al. (2015b) analyzing the segregation of the blood-flesh trait attribute (due to anthocyanin accumulation) in a peach landrace Dahongpao showed that PpMYB10.1 did not co-segregate with this trait (Zhou et al., 2015b). However, by heterologous expression in tobacco, they found that BLOOD (BL), a NAC transcription factor, and PpNAC1 act together to 
transactivate the PPMYB10.1 gene. PPSPL1, a SQUAMOSA promoter-binding protein-like transcription factor (SPL), represses this transactivation. Another R2R3-MYB gene regulating $\mathrm{PA}$ synthesis in peach is $P P M Y B 7$, which activates the transcription of $P p L A R 1$ but not $P p A N R$. $P p M Y B 7$ promoter has an ABA-dependent DRE2 element and it can be activated by the basic leucine-zipper 5 TF PpbZIP5 via the ABA signaling (Zhou et al., 2015a).

In peach, anthocyanin accumulation is also influenced by light quality (including UV-B, UV-A, blue light and (far) red light) and depends on the genetic background (Liu T. et al., 2015). The expression of bHLH3 also correlated with induction of anthocyanin synthesis in peach peel under UV exposure (Zhao et al., 2017). Light effect is likely mediated by $\mathrm{PpHYH}$ that is also homologous to A. thaliana HY5, rather than by PpHY5 (Zhao et al., 2017). In addition, ppa009438m, ppa009380m, ppa026582m, ppa007883m, and ppa025263m encoding PpNACs responded to UV-B light. Nevertheless, $B L$ and $P$ PNAC1 did not respond to UV-B treatment in 'Hujingmilu' and 'Yulu' cultivars (Zhao et al., 2017). Therefore, the levels of anthocyanin in peach fruit are complexly controlled by the coordination of a set of transcription factors.

Other transcription factors such as PpMYBPA1 (ppa009439m) and Peace (ppa023768m) that is phylogenetically related to PpMYBPA1, have been identified in RNAseq studies and related to the regulation of proanthocyanin (PA) biosynthesis in peach fruit (Wang et al., 2013). PpMYBPA1, as in the case of PpMYB7, can be activated by PpbZIP5 via the ABA signaling (Zhou et al., 2015a). In flowers, PpMYBPA1 and Peace were to be expressed at bud stage and were shown to activate $P p L A R$ and $P p A N R$ promoters (Zhou et al., 2016).

While many advances have been conducted to elucidate the transcription factors controlling anthocyanin accumulation in peach, less information is available with respect to apricot. Some cultivars have blushed skin due to the presence of cyanidin-3-Oglucoside, cyanidin-3-O-rutinoside, and peonidin-3-Orutinoside. Thus, anthocyanin presence and accumulation depend on the cultivar. In apricot, PaMYB10 also correlated with anthocyanin accumulation in blushed apricots and with PaMYB10, PaPAL, PaCHS, PaCHI, PaF3H, PaDFR, PaLDOX, and PaUFGT. The overexpression of this MYB transcription factor in fruits of Luntaixiaobaixing cultivar conducted the red coloration of the skin. PaMYB10 was found to be located with Linkage group 3 (G3) related to skin color (García-Gómez et al., 2019). In addition, it was probed that anthocyanin accumulation in apricot was also influenced by light, as fruit bagging affects the coloration of the skin (Xi et al., 2019). Sugars were also correlated with the content of cyanidin-3-O-glucoside and cyanidin-3-Orutinoside; as it the case of sorbitol, glucose, fructose and sucrose (Huang et al., 2019). Further studies are required to decipher the way in which sugars affect anthocyanin synthesis in apricot.

In sweet cherry, the expression of PacCHS, PacCHI, PacF3H, PacDFR, PacANS, and PacUFGT correlated with anthocyanin accumulation (Liu et al., 2013). The regulation of this pathway has started to emerge. Sequencing of cDNAs encoding enzymes involved in the synthesis of anthocyanins or their regulators
(bHLH and WD40) confirms the conservation at sequence level within the Prunus genus (Starkevic et al., 2015). Up to now, PavMYB10, PavMYBA, and PavMYB1 have been studied in sweet cherries (Lin-Wang et al., 2010; Shen et al., 2014; Starkevic et al., 2015; Jin et al., 2016). The first transcription factor modulating the pathway characterized was PavMYB10, which was probed to correlate with anthocyanin accumulation in fruit (Lin-Wang et al., 2010). Two sub-variants of PaMY10.1, PaMYB10.1-1 and -3, were later studied. By studying fruits at different stages of development from different cultivars of $P$. avium, Starkevic et al. (2015) indicated that PaMYB10.1-1 parallels that of anthocyanin accumulation and that PaMYB10.1-3 is expressed at low levels in fruit. Nevertheless, when transiently expressed in tobacco, PaMYB10.1-3 was able to induce pigment synthesis. It was also shown that PavMYB10.1 has three alleles PavMYB10.1a-to -c. These alleles are responsible for the variation in color of the fruit. PavMYB10.1a regulates the expression of PavANS and PavUFGT by binding with PavbHLH and PavWD40 (Jin et al., 2016). Jin et al., 2016 proposed that PavMYB10.1 is a DNA molecular marker for the color of the skin.

With respect to bHLHs, PabHLH3 and -33 are expressed in fruit. While PabHLH3 co-activates anthocyanin biosynthesis in the presence of MYB, PabHLH33 acts as a co-repressor (Starkevič et al., 2015). In addition, PavMYBA, encoding for a R2R3-MYB TF from red-colored sweet cherry, was studied. Transient assays demonstrated that this factor binds to bHLHs and activates the expression of PavDFR, PavANS, and PavUFGT. In addition, ABA modulated the synthesis of anthocyanins in cherry fruit, with PavMBA involved in this process (Shen et al., 2014).

\section{Terpenoids}

The terpenoids or isoprenoids constitute a large group of metabolites derived from $\mathrm{C}_{5}$ isoprene (2-methyl-1,3-butadiene) formed by "head-to-tail" conjugation. Terpenoids fulfill varied biological functions in plants, from essential roles as electron transport chain components, pigments (carotenoids, and chlorophylls), elements of membrane structure and function (phytosterols), hormones (i.e. gibberellins, strigolactones, brassinosteroids, abscisic acid, isopronoids cytokinins), protein glycosylation (dolichols), to defense (antimicrobial/anti-insect) and attractants (volatile signals) (Tholl, 2015; Tarkowská and Strnad, 2018; Block et al., 2019). Volatile terpenoids (i.e. Rlimonene) are the major class of volatile compounds in plants and are predominantly isoprenes, mono- and sesquiterpenes. Volatile terpenoids have been found in roots, stems, leaves, fruits, seeds and to higher extent in flowers. In fruits, these terpenoids contribute to aroma production (Dudareva et al., 2013; Abbas et al., 2017).

Biosynthesis and functions of isoprenoids have been well characterized and extensively reviewed (Tholl, 2015; Yazaki et al., 2017; Tarkowská and Strnad, 2018). According to their number of units they can be divided into mono- $\left(\mathrm{C}_{10}\right)$, sesqui- $\left(\mathrm{C}_{15}\right)$, di- $\left(\mathrm{C}_{20}\right)$, sester- $\left(\mathrm{C}_{25}\right)$, tri- $\left(\mathrm{C}_{30}\right)$, tetra- $\left(\mathrm{C}_{40}\right.$, carotenoids $)$, and polyterpenes $\left(>C_{40}\right)$ (Tholl, 2015). The combination of isoprene units, in the 
form of dimethylallyl diphosphate (DMAPP) and its isomer isopentenyl diphosphate (IPP), conducts the synthesis of the building blocks geranyl diphosphate (GPP), farnesyl diphosphate (FPP) and geranylgeranyl diphosphate (GGPP, Figure 3). These precursors are synthesized by two distinct pathways: the mevalonate (MVA) and the nonmevalonate pathways. The last route is also called the 2-C-methyl-d-erythritol 4-phosphate (MEP) or the 1-deoxy-d-xylulose 5-phosphate pathway (DOXP). MVA derives from mevalonate synthesized from acetyl-CoA, while MEP derives from pyruvate. GPP, FP, and GGPP are the precursors in the synthesis of mono-, sesqui- and diterpenes, respectively (Tholl, 2015). Then, terpene synthases (TPSs) and cytochrome P450s are the main enzymes that generate the huge terpenoid diversification using mono-, sesqui-, and diterpenes. Other enzymes also contribute to the array of chemically diverse terpenoids.

To mention an example of biosynthesis, carotenoids are synthesized from GGPP using phytoene synthase (PSY) which condenses two molecules of GGPP to render 15-cis phytoene. The following enzymes in the route are phytoene desaturase (PDS), 15-cis- $\zeta$-carotene isomerase (ZISO), $\zeta$-carotene desaturase (ZDS), and carotenoid isomerase (CRTISO) giving trans-lycopene (Liang et al., 2018). Lycopene is the precursor of many molecules of biological importance, the $\delta$-, $\gamma_{-}, \alpha_{-}, \epsilon_{-}^{-}$, and $\beta$-carotenes. Carotenes are also important precursors; lutein and xanthopylls derive from $\alpha$ - and $\beta$-carotene, respectively (for further details, see Liang et al. (2018)). Apocarotenoids are the result of the oxidative cleavage of carotenoids. Examples of apocarotenoids are the derivatives of $\beta$-ionone that have pleasant scent and aroma in fruits and flowers (Hou et al., 2016). While many efforts have been dedicated to the elucidation of carotenoid metabolism in plant species, little is known about the regulation (Pott et al., 2019).

Regulation of carotenogenesis has been exhaustively investigated in tomato fruit and Arabidopsis, and it has been also comprehensively reviewed (Llorente et al., 2017; Stanley and Yuan, 2019). Transcription factors such as phytochrome interacting factors (PIFs), ethylene response factors (ERFs), MADS ripening inhibitor factor (RIN) are some of the many TFs that modulate carotenoids synthesis. Both environmental conditions (i.e. light) and developmental cues control the carotenoid biosynthetic genes (Llorente et al., 2016; Sun et al., 2018). The control of carotenoid accumulation is also exerted at posttranscriptional and posttranslational levels (Stanley and Yuan, 2019). Biosynthesis, degradation, and storage mediate carotenoids homeostasis as well (Li and Yuan, 2013).

The first study of regulation of carotenoids' synthesis regulation in apricot was conducted comparing varieties with contrasting colors. It showed similar regulation of the synthesis of the colorless carotenoids phytoene and phytofluene due to ethylene upregulation of PSY1 and PDS. In this study, while great differences in $\beta$-carotene levels were found in two varieties, accumulation of ZDS was found in both varieties (Marty et al., 2005). Further, RNAseq analysis revealed that structural genes like PDS1, carotenoid cleavage dioxygenase (CCD) 1 and 4, violaxanthin de-epoxidase 1 (VDE1) and zeaxanthin epoxidase (ZEP) are the main regulatory points for carotenogenesis (Zhang

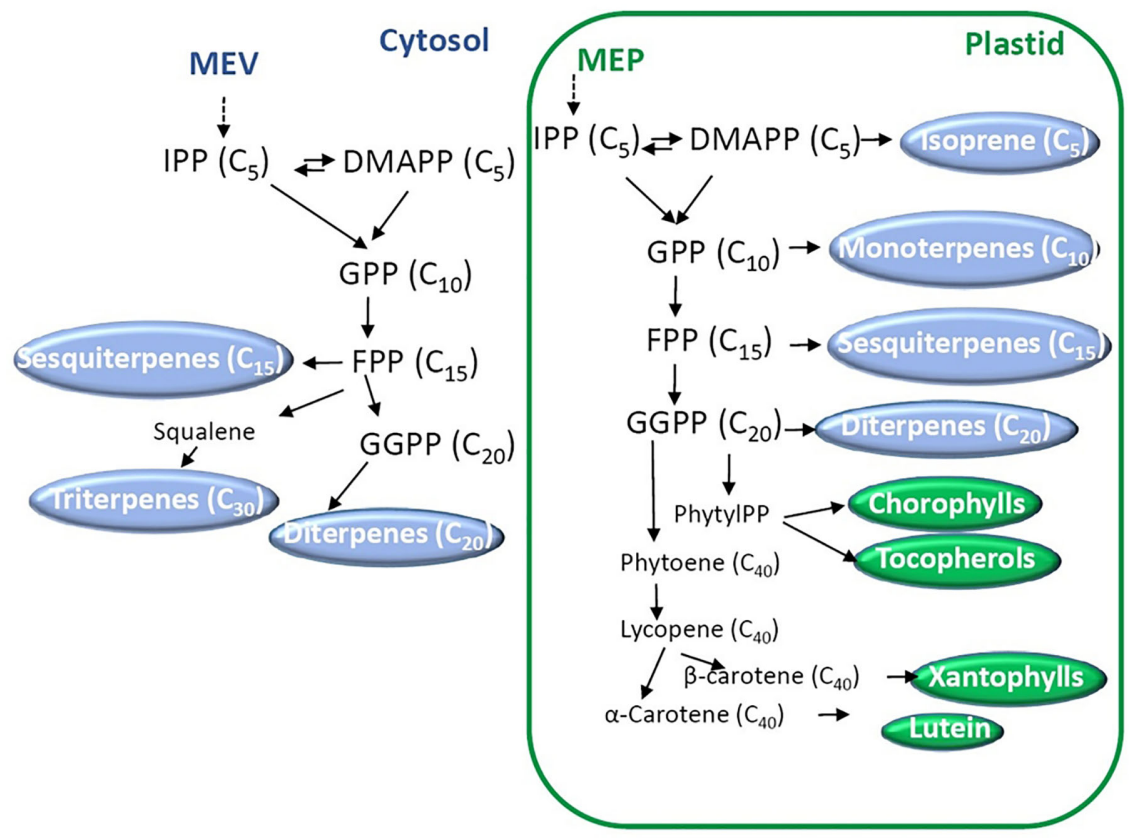

FIGURE 3 | Biosynthesis of terpenoids. Two main pathways starting from mevalonate (MEP) and 2-C-methyl-d-erythritol 4-phosphate (MEP) occur in the cytosol and the plastids, respectively. Dimethylallyl diphosphate (DMAPP) and its isomer isopentenyl diphosphate (IPP) are the isoprene units that conduct the synthesis of the building blocks geranyl diphosphate (GPP), farnesyl diphosphate (FPP), and geranylgeranyl diphosphate (GGPP). The number of carbons of each molecule is indicated between brackets. 
et al., 2019). Network analysis indicates the presence of two modules for gene expression for carotenoids synthesis in apricots. A set of transcription factors integrating hormones such as ethylene and brassinosteroids (ERF4/5/12, AP2, AP2-like and BZR1), developmental factors (MADS14, NAC2/25, MYB1R1/44, GLK1/2 and WRKY6/31/69) and light (PIF3/4 and HY5) possibly modulate carotenoid accumulation during ripening (Zhang et al., 2019).

In peach, studies regarding carotenoid accumulation in the mesocarp have been focused on carotenoid cleavage. CCDs control carotenoid degradation, and therefore color accumulation. PpCCD4 encodes a carotenoid dioxygenase. High transcript levels increase carotenoid degradation producing colorless compounds and thus, rendering white flesh. PpCCD4 is also associated with synthesis of carotenoidderived volatiles (Brandi et al., 2011; Adami et al., 2013; Falchi et al., 2013). In the mentioned studies and in Cao et al. (2017), although carotenoid synthesis is linked to their biosynthetic enzymes, correlation between biosynthetic genes' expression and carotenoid levels was not found. What is clear is that the levels of PpCCD4 increase in the flesh and the pulp of white varieties during development and ripening. Yellow varieties are characterized by a combination of higher levels of PpPDS and lower accumulation of PpCCD4 with respect to the white ones (Cao et al., 2017). In addition, while blue light treatment applied during storage was effective to stimulate the transcription of carotenoid biosynthetic genes in both yellow and white varieties, it was able to induce carotenoid accumulation only in yellow but not in white peach, indicating that in white peach the levels of main carotenoid biosynthetic genes are not the primary factor regulating carotenoid amounts (Cao et al., 2017).

\section{Nitrogen- and Sulfur-Containing Secondary Metabolites}

The third group of secondary metabolites is large and diverse. It includes alkaloids, glucosinolates, and cyanogenic glucosides.

Glucosinolates are nitrogen- and sulfur-containing metabolites generally restricted to the Brassicales (Grubb and Abel, 2006). Glucosinolates are diverse and their derivatives participate in plant defense and contribute to flavor and aroma (Grubb and Abel, 2006).

Alkaloids are nitrogenous compounds of low molecular weight derived mostly from amino acids (Ziegler and Facchini, 2008). This is a diverse group with a wide range of biological functions. According to their structure, alkaloids can be classified into "true" alkaloids with a heterocyclic nitrogen, protoalkaloids (no cyclic nitrogen), and pseudoalkaloids (e.g., steroidal and diterpene alkaloids, caffeine) (Waterman, 1998). The different biosynthetic pathways are in accord to their diversity in structure (Ziegler and Facchini, 2008).

Cyanogenic glycosides participate in plant defense and are widely distributed in the plant kingdom (Zagrobelny et al., 2008). The basic structure is a carbon backbone derived from an amino acid and a glycosilated cyanohydrin. The participation in plant defense mechanisms relays on the hydrolytic release of hydrocyanic acid potentially toxic to herbivores $(\mathrm{HCN})$
(Drochioiu et al., 2008). The occurrence of cyanogenic glycosides has been described in species of the Fabaceae, Poaceae, Rosaceae, and Asteraceae, and also in conifers and ferns (Gleadow and Møller, 2014). Seeds from stone fruits of the Rosaceae family are rich in diglucoside (R)-amygdalin (Swain et al., 1992). In addition to kernels, the monoglucoside prunasin is also found in leaves, roots, stems (Dicenta et al., 2002; Sánchez-Pérez et al., 2008). Both compounds are synthesized from phenylalanine. The sequential action of two cytochrome P450 enzymes belonging to the CYP79 and CYP71 families catalyze the synthesis of mandelonitrile (Yamaguchi et al., 2014), which is then glucosylated by a UDPglycosyltransferase (UGT) to form prunasin. This compound is then glucosylated again to form amygdalin.

In Prunus dulcis, two genes PdCYP79D16 and PdCYP71AN24 encoding CYP79 and 71 and three genes encoding UGTs involved in amygdalin (PdUGT94AF1 and PdUGT94AF2) and prunasin synthesis (PdUGT94AF3) were identified. The functionality and activities of the proteins were tested by expression in Nicotiana benthamiana. Comparisons of sweet and bitter almonds, which differentially accumulate amygdalin, indicated that the expression of PdCYP79D16 and PdCYP71AN24 is very low or null in the tegument of the sweet genotype and high in the bitter almonds (Thodberg et al., 2018). More recently, using map-based cloning and a segregating population for sweet kernel trait Sánchez-Pérez and colleagues (2019) identified that bHLH2 controls the expression of PdCYP79D16 and PdCYP71AN24. A mutation in bHLH2 avoids the transcription of both genes, and thus mandelonitrile, amygdalin and prunasin are not synthesized. Selection of this mutation is proposed to have allowed the domestication of almond (Sánchez-Pérez et al., 2019).

\section{STONE FRUITS AS A SOURCE OF PHYTOCHEMICALS: A DESCRIPTION OF SECONDARY ORGANIC COMPOUNDS' COMPOSITION OF MAIN STONE FRUITS}

\section{Peach}

Phenolic compounds are the main source of antioxidant capacity in peaches (Gil et al., 2002). They also participate in the visual appearance (pigmentation and browning) (Lee et al., 1990) and in the taste (astringency) of fruits (Tomás-Barberán et al., 2001) and therefore could be used to evaluate the quality of the fruit. In peaches, carotenoids are responsible for the yellow color of the pulp, and therefore, their concentration is low in white pulp fruits (Gil et al., 2002). Peaches contain anthocyanins (cyanidin3-glucoside and cyanidin-3-rutinoside), flavan-3-ols (catechinthe main monomeric flavan-3-ol-, epicatechin, epigallocatechin, and procyanidins), flavonols (quercetin-3-O-rutinoside or rutin, quercetin-3-glucoside, quercetin-3-galactoside, kaempferol3-rutinoside), hydroxycinnamic acids (chlorogenic and neoclorogenic acids) (Campbell and Padilla-Zakour, 2013; Dabbou et al., 2017), and the main carotenoids include $\beta$ carotene and xanthophylls (mono- or di-hydroxylated carotenoids), zeaxanthin, $\beta$-cryptoxanthin and violaxanthin (Tomas-Barberan 
et al., 2001; Campbell and Padilla-Zakour, 2013; Dabbou et al., 2017), and lutein (Oliveira et al., 2016). Amounts of some of the most representative phytochemicals present in the pulp of peach of different cultivars at commercial maturity are shown in Table $\mathbf{1}$.

More than 100 volatile compounds have been identified in peach fruit. Volatile organic compounds define fruit aroma and participate, together with organic acids and sugars, in fruit taste. Aroma is a central trait that influences the fruit quality perception by consumers (Bruhn et al., 1991). In addition, volatile composition gives significant information regarding healthful composition of food since they are synthesized from essential nutrients (Goff and Klee, 2006). Peach volatiles have been classified into alcohols, aldehydes, carboxylic acids, noncyclic esters, terpenoids, ketones, and lactones (Wang et al., 2009; Sánchez et al., 2012). The most abundant are $\mathrm{C}_{6}$ compounds, esters, benzaldehyde, linalool, $\mathrm{Cl}_{3}$ norisoprenoids, and lactones. The amounts of benzaldehyde, linalool, $\delta$-decalactone and (E)-2hexenal in four peach cultivars are presented in Table 2 to show their variability among cultivars.
Lactones such as $\gamma$-decalactone, c-jasmolactone c-octalactone, c-dodecalactone, $\delta$-decalactone and 6-pentyl- $\alpha$-pyrone have been described as the key odorants to the pleasant aroma of peach fruit, with $\gamma$-decalactone most highly associated with the "peach-like" note. In addition, the esters (Z)-3-hexenyl acetate, (E)-2-hexen-1-ol acetate, and ethyl acetate add to the "fruity" notes. Moreover, linalool and $\beta$-ionone and other terpenoids contribute to the "floral" notes (Horvat et al., 1990; Derail et al., 1999; Eduardo et al., 2010).

During industrial processing of peach to produce juices, marmalades, concentrates and canned fruit, peel and stone are removed and discarded. Likewise, most of the times that fruit is freshly consumed; the peel is also discarded because of the use of chemicals and pest contamination or digestion problems. Nevertheless, both peels and kernels are a source of bioactive compounds. Indeed, many phytochemicals are more abundant in the fruit peel than in the edible fleshy parts. For example, phenolics (Tomás-Barberán et al., 2001), carotenoids, and ascorbic acid double their amount in the peel than in the pulp

TABLE 1 | Amounts of some of the most representative phytochemicals present in the pulp of peach, plum, apricot, and cherry at commercial maturity.

\begin{tabular}{|c|c|c|c|c|c|c|c|c|}
\hline \multirow[b]{2}{*}{ Neochlorogenic acid } & \multicolumn{2}{|c|}{ Prunus persica } & \multicolumn{2}{|c|}{ Prunus salicina } & \multicolumn{2}{|c|}{ Prunus armeniaca } & \multicolumn{2}{|c|}{ Prunus avium } \\
\hline & Annongshuimi & $2.6^{\mathrm{C}}$ & Keckemetska ruza & $1.19^{l}$ & Early Magic & $18.1^{i}$ & Burlat & $21.7^{\mathrm{s}}$ \\
\hline & Huyou0 002 & $23.2^{\mathrm{C}}$ & Madjarska najbolja & $1.42^{\prime}$ & Beltsville Elite B70197 & $215.4^{i}$ & Saco & $190^{\mathrm{s}}$ \\
\hline & Huyou0 018 & $7.8^{\mathrm{c}}$ & Velika rana & $1.22^{\prime}$ & NY101 & $179.4^{i}$ & Summit & $40.4^{s}$ \\
\hline & Sweet cap & $5.8^{\mathrm{d}}$ & Bebecou & $1.37^{\mathrm{m}}$ & Brite pearl & $183^{j}$ & Badascony & $4.74^{t}$ \\
\hline & Ealy May Crest & $5.0^{d}$ & Nafsika & $0.41^{\mathrm{m}}$ & September red & $24.1^{j}$ & Early Van Comact & $11.9^{t}$ \\
\hline & O'Henry & $4.1^{d}$ & Niove & $1.57^{\mathrm{m}}$ & Spring Bright & $36.7^{j}$ & Vigred & $6.50^{t}$ \\
\hline & Big Top & $2.3^{\mathrm{e}}$ & Z 109/58 & $3.8^{n}$ & Laetitia & $39.6^{k}$ & Della Marca & $0.96^{\mathrm{u}}$ \\
\hline & Royal Glory & $1.5^{\mathrm{e}}$ & Rojo passion & $10.68^{n}$ & Ruby Red & $40.1^{k}$ & Lapins & $6.17^{\mathrm{u}}$ \\
\hline & Red Haven & $4.7^{\mathrm{e}}$ & Z 505/2 & $6.4^{\mathrm{n}}$ & African delight & $39.1^{\mathrm{k}}$ & Moretta & $7.31^{\mathrm{u}}$ \\
\hline \multirow[t]{9}{*}{ Chlorogenic acid } & Annongshuimi & $4.1^{\mathrm{c}}$ & Keckemetska ruza & $1.47^{\prime}$ & Brite pearl & $277^{j}$ & Burlat & $3.65^{s}$ \\
\hline & Huyou0 002 & $31.1^{\mathrm{c}}$ & Madjarska najbolja & $2.29^{1}$ & September red & $39^{j}$ & Saco & $12^{s}$ \\
\hline & Huyou0 018 & $23.3^{\mathrm{C}}$ & Velika rana & $1.93^{\prime}$ & Spring Bright & $84.3^{j}$ & Summit & $9.73^{\mathrm{s}}$ \\
\hline & Sweet cap & $8.9^{d}$ & Bebecou & $1.01^{\mathrm{m}}$ & Early Magic & $0.9^{i}$ & Badascony & $1.12^{t}$ \\
\hline & Ealy May Crest & $8.5^{\mathrm{d}}$ & Nafsika & $0.46^{\mathrm{m}}$ & Beltsville Elite B70197 & $9.5^{i}$ & Early Van Comact & $2.26^{t}$ \\
\hline & O'Henry & $5.6^{d}$ & Niove & $2.2^{\mathrm{m}}$ & NY101 & $21.0^{i}$ & Vigred & $1.07^{t}$ \\
\hline & Big Top & $0.21^{\mathrm{e}}$ & Z 109/58 & $6.9^{n}$ & Laetitia & NDK & Della Marca & $22.83^{\mathrm{u}}$ \\
\hline & Royal Glory & $0.44^{\mathrm{e}}$ & Rojo passion & $11.0^{n}$ & Ruby Red & $N D^{k}$ & Lapins & $149.89^{4}$ \\
\hline & Red Haven & $0.35^{\mathrm{e}}$ & Z 505/2 & $7.6^{n}$ & African delight & $2.5^{\mathrm{k}}$ & Moretta & $68.4^{\mathrm{u}}$ \\
\hline \multirow[t]{9}{*}{ Rutin } & Annongshuimi & $N D^{c}$ & Bebecou & $9.37^{\mathrm{m}}$ & Brite pearl & $27.2^{\star}$ & Burlat & $3.06^{s}$ \\
\hline & Huyou0 002 & $N^{c}$ & Nafsika & $5.65^{\mathrm{m}}$ & September red & $41.8^{\star j}$ & Saco & $13.69^{s}$ \\
\hline & Huyou0 018 & $N^{c}$ & Niove & $7.73^{\mathrm{m}}$ & Spring Bright & $56.9^{\star j}$ & Summit & $2.81^{\mathrm{s}}$ \\
\hline & Sweet cap & $0.25^{d}$ & 'Keckemetska ruza & $2.02^{\prime}$ & Early Magic & $6.3^{i}$ & Badascony & $5.78^{t}$ \\
\hline & Ealy May Crest & $0.13^{d}$ & Madjarska najbolja & $1.55^{1}$ & Beltsville Elite B70197 & $4.3^{\mathrm{i}}$ & Early Van Comact & $3.53^{t}$ \\
\hline & O’Henry & $0.14^{d}$ & Velika rana & $2.17^{\prime}$ & NY101 & $5.0^{i}$ & Vigred & $5.68^{t}$ \\
\hline & Big Top & $1.8^{\mathrm{e}}$ & LE-2927 & $12.16^{\star}$ & Laetitia & $6.6^{\mathrm{k}}$ & Della Marca & $5.13^{\mathrm{u}}$ \\
\hline & Royal Glory & $0.99^{e}$ & Salah-Jerevan & $5.41^{\circ}$ & Ruby Red & $7.9^{k}$ & Lapins & $51.97^{\mathrm{u}}$ \\
\hline & Red Haven & $0.8^{\mathrm{e}}$ & Chuan Zhi Hong & $56.9^{\circ}$ & African delight & $7.4^{\mathrm{k}}$ & Moretta & $41.4^{\mathrm{u}}$ \\
\hline \multirow[t]{9}{*}{ Cyanidin-3- rutinoside } & Annongshuimi & $3.5^{\mathrm{c} \$}$ & Z 115/26 & $1.6^{n}$ & Early Magic & $18.9^{i}$ & Burlat & $28.5^{\mathrm{s}}$ \\
\hline & Huyou0 002 & $1.3^{\mathrm{c} \$}$ & Rojo passion & $4.4^{n}$ & Beltsville Elite B70197 & $25.7^{i}$ & Saco & $24.5^{s}$ \\
\hline & Huyou0 018 & $3.8^{\mathrm{c} \$}$ & Z 505/2 & $2.9^{n}$ & Longjohn & $33.0^{i}$ & Summit & $20.1^{\mathrm{s}}$ \\
\hline & Sweet cap & $0.028^{d}$ & & & Brite pearl & $3.5^{\star j}$ & Badascony & $12.8^{t}$ \\
\hline & Ealy May Crest & $0.011^{d}$ & & & September red & $4.6^{\star j}$ & Early Van Comact & $8.06^{t}$ \\
\hline & O'Henry & $1.148^{d}$ & & & Spring Bright & $12.7^{\star j}$ & Vigred & $13.5^{t}$ \\
\hline & Big Top & $0.47^{\mathrm{e} \$}$ & & & Laetitia & $1.48^{k}$ & Della Marca & $2.05^{\mathrm{u}}$ \\
\hline & Royal Glory & $0.67^{\mathrm{e} \$}$ & & & Ruby Red & $2.81^{k}$ & Lapins & $389.9^{\mathrm{u}}$ \\
\hline & Red Haven & $0.42^{\mathrm{e} \$}$ & & & African delight & $1.51^{k}$ & Moretta & $268.2^{u}$ \\
\hline
\end{tabular}

The amounts of chlorogenic and neochlorogenic acids (hydroxycinnamic acids), quercetin-3-O-rutinoside or rutin (flavonol) and cyanidin-3-rutinoside (anthocyanins) are indicated in different cultivars and expressed in $\mathrm{mg} / 100 \mathrm{~g}$ of fresh weight.

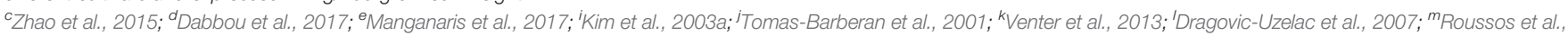
2011; " Ruiz et al., 2005: 'Schmitzer et al., 2011; ' Goncàlves et al., 2004; 'Usenik et al., 2008; "Martini et al., 2017. 
TABLE 2 | The most abundant or representative volatiles (benzaldehyde, linalool, trans-linalool oxide, $\gamma$-decalactone, $\delta$-decalactone, hexanal, (E)-2-hexenal, hexanol, 2-Hexen-1-ol and hexyl acetate) in the pulp of different cultivars of peach, plum, apricot, and cherry at commercial maturity are expressed in $\mu \mathrm{g} / \mathrm{kg}$ of fresh weight.

\begin{tabular}{|c|c|c|}
\hline \multicolumn{3}{|c|}{ Prunus persica } \\
\hline \multirow[t]{4}{*}{ 2-Hexenal } & Western red & $1,381 \cdot 1^{\mathrm{a}}$ \\
\hline & Chongyanghong & $2,332^{\& b}$ \\
\hline & Zaohongxia & $3,228^{8 b}$ \\
\hline & Wuyuehuo & $7078^{\& b}$ \\
\hline \multirow[t]{4}{*}{ Benzaldehyde } & Western red & $61.9^{\mathrm{a}}$ \\
\hline & Chongyanghong & $1,187.8^{8 b}$ \\
\hline & Zaohongxia & $2,918.4^{8 b}$ \\
\hline & Wuyuehuo & $1,080.4^{8 b}$ \\
\hline \multirow[t]{4}{*}{ Linalool } & Western red & $50.2^{\mathrm{a}}$ \\
\hline & Chongyanghong & $285.9^{8 b}$ \\
\hline & Zaohongxia & $680.2^{8 b}$ \\
\hline & Wuyuehuo & $759.3^{8 b}$ \\
\hline \multirow[t]{4}{*}{$\delta$-decalactone } & Western red & $16.3^{\mathrm{a}}$ \\
\hline & Chongyanghong & $1,904.5^{\& b}$ \\
\hline & Zaohongxia & $1,368.5^{8 b}$ \\
\hline & Wuyuehuo & $1,843.0^{2 b}$ \\
\hline \multicolumn{3}{|c|}{ Prunus armeniaca } \\
\hline \multirow[t]{9}{*}{ (E)-2-Hexenal } & Palstey & $4,635^{\mathrm{p}}$ \\
\hline & Moniqui & $26,800^{p}$ \\
\hline & Rouge du Roussillo & $8,752^{p}$ \\
\hline & Early Blush Rutbhart & $133^{q}$ \\
\hline & Spring Blush EA3126TH & $59^{q}$ \\
\hline & PBS 28-58 & $153^{q}$ \\
\hline & K604-19 & $N^{r}$ \\
\hline & $\mathrm{K} 113-40$ & $N D^{r}$ \\
\hline & K33-81 & $N^{r}$ \\
\hline \multirow[t]{9}{*}{ Linalool } & Palstey & $3,019^{p}$ \\
\hline & Moniqui & $1,021^{p}$ \\
\hline & Rouge du Roussillo & $864^{p}$ \\
\hline & Early Blush Rutbhart & $80^{q}$ \\
\hline & Spring Blush EA3126TH & $256^{q}$ \\
\hline & PBS 28-58 & $43^{q}$ \\
\hline & K604-19 & $671^{r}$ \\
\hline & $\mathrm{K} 113-40$ & $365^{r}$ \\
\hline & K33-81 & $150^{r}$ \\
\hline \multirow[t]{9}{*}{$\delta$-decalactone } & Palstey & $2526^{p}$ \\
\hline & Moniqui & $37,310^{p}$ \\
\hline & Rouge du Roussillo & $21,024^{\mathrm{P}}$ \\
\hline & Early Blush Rutbhart & $454^{9}$ \\
\hline & Spring Blush EA3126TH & $105^{q}$ \\
\hline & PBS 28-58 & $281^{a}$ \\
\hline & K604-19 & $1,424^{r}$ \\
\hline & K113-40 & $3^{r}$ \\
\hline & K33-81 & $50 r$ \\
\hline \multirow[t]{9}{*}{ Hexyl acetate } & Palstey & $5,244^{\mathrm{P}}$ \\
\hline & Moniqui & $1,250^{\mathrm{p}}$ \\
\hline & Rouge du Roussillo & $13,140^{p}$ \\
\hline & Early Blush Rutbhart & $54^{9}$ \\
\hline & Spring Blush EA3126TH & $2^{q}$ \\
\hline & PBS 28-58 & $3^{q}$ \\
\hline & K604-19 & $N^{r}$ \\
\hline & $\mathrm{K} 113-40$ & $N D^{r}$ \\
\hline & K33-81 & $4^{r}$ \\
\hline \multicolumn{3}{|c|}{ Prunus salicina } \\
\hline \multirow[t]{2}{*}{ 2-Hexenal } & Horvin & $72^{\mathrm{g}}$ \\
\hline & Range & $1.03^{h}$ \\
\hline 1-Hexanol & Showtime & $861^{f}$ \\
\hline
\end{tabular}

(Continued)
TABLE 2 | Continued

\begin{tabular}{|c|c|c|}
\hline & Laetitia & $1,370^{f}$ \\
\hline & Primetime & $1210^{f}$ \\
\hline & Horvin & $1,739.7^{9}$ \\
\hline & Range & $2.11^{\mathrm{h}}$ \\
\hline \multirow[t]{5}{*}{ Hexanal } & Showtime & $1,500^{f}$ \\
\hline & Laetitia & $1,850^{f}$ \\
\hline & Primetime & $2,420^{f}$ \\
\hline & Horvin & Traces $^{g}$ \\
\hline & Range & $7.67^{\mathrm{h}}$ \\
\hline \multirow[t]{4}{*}{ trans-Linalool oxide } & Primetime & $185^{f}$ \\
\hline & Laetitia & $262^{f}$ \\
\hline & Showtime & $726^{f}$ \\
\hline & Horvin & $102.2^{\mathrm{g}}$ \\
\hline \multicolumn{3}{|l|}{ Prunus avium } \\
\hline (E)-2- & Van & $412.71^{v}$ \\
\hline \multirow[t]{5}{*}{ Hexenal } & Vista & $45.53^{v}$ \\
\hline & 0-900Ziraat & $269.50^{v}$ \\
\hline & Canada & $2.56^{w}$ \\
\hline & Ferrovia & $6.36^{w}$ \\
\hline & Lapins & $2.60^{w}$ \\
\hline \multirow[t]{6}{*}{ Benzaldehyde } & Van & $10.10^{v}$ \\
\hline & Vista & $7.69^{v}$ \\
\hline & 0-900Ziraat & $20.52^{v}$ \\
\hline & Canada Giant & $0.45^{w}$ \\
\hline & Ferrovia & $0.50^{w}$ \\
\hline & Lapins & $1.06^{\mathrm{w}}$ \\
\hline \multirow[t]{6}{*}{ Hexanal } & Van & $122.96^{v}$ \\
\hline & Vista & $25.75^{v}$ \\
\hline & 0-900Ziraat & $144.66^{v}$ \\
\hline & Canada Giant & $0.71^{w}$ \\
\hline & Ferrovia & $2.72^{w}$ \\
\hline & Lapins & $0.62^{w}$ \\
\hline \multirow[t]{6}{*}{ 2-Hexen-1-ol } & Van & $172^{v}$ \\
\hline & Vista & $14.64^{v}$ \\
\hline & 0-900Ziraat & $83.77^{\mathrm{V}}$ \\
\hline & Canada Giant & $1.02^{w}$ \\
\hline & Ferrovia & $1.04^{w}$ \\
\hline & Lapins & $0.78^{w}$ \\
\hline
\end{tabular}

\& the ripening stage is not specified in the literature; ND, not detected; ${ }^{a}$ Aubert et al., 2014; ${ }^{b}$ Zhu and Xiao, 2019; ${ }^{f}$ Cuevas et al., 2016; ${ }^{g}$ Pino and Quijano, 2012; ${ }^{h}$ Chai et al., 2012; ${ }^{P}$ Guichard and Souty, 1988; ' Aubert and Chanforan, 2007; ' 'Gómez et al., 1993;

${ }^{v}$ Hayaloglu and Demir, 2015; "'Vavoura et al., 2015.

(Gil et al., 2002). Dabbou et al. (2017) showed that irrespective of the ripening stage, hydroxycinnamic acids, total flavonols, and total anthocyanins are higher in the peel than in the pulp. In contrast, the relative content of carotenoids depended on the harvesting stage.

Peach kernels provide seed oil and fatty acids (Wu et al., 2011). In addition, kernels are a source of a wide range of metabolites of nutritional importance. The following secondary metabolites have been identified in peach kernels: protocatechuic acid, $p$-hydroxybenzoic acid, $p$-hydroxyphenylacetic acid, dihydroxybenzoic acid, chlorogenic acid, $p$-coumaric acid, ferulic acids, dithiothreitol, rutin, caffeic acid, procyanidin B2, hydrocinnamic acid, procatechol, catechin, gentisic acid, kuromanin chloride, vanillic acid, epicatechin gallate, sinapinic acid, and ellagic acid (Wu et al., 2011 and Koprivica et al., 2018), with catechin being prevalent.

Much effort has been dedicated to the characterization of the volatilome of peach as well as the profiling of other secondary 
metabolites in stone fruits (Horvat et al., 1990; Visai and Vanoli, 1997; Derail et al., 1999; Eduardo et al., 2010; Sánchez et al., 2012). In addition, in the case of volatiles, some QTLs have been identified (Sánchez et al., 2014).

\section{Apricot}

Apricot is a good source of carotenoids (Zaghdoudi et al., 2015), fatty acids, and sterols, volatile compounds, glycosides and polyphenols (Erdogan-Orhan and Kartal, 2011). Lutein, $\alpha$ and $\beta$-carotenes are the main carotenoids of apricot fruit (Erdogan-Orhan and Kartal, 2011; Katayama et al., 2011). $\beta$ carotene accounts for $60-70 \%$ of the total carotenoid content (Dragovic-Uzelac et al., 2007). Apricot is also a rich source of the carotenoid's precursors phytoene and phytofluene (Biehler et al., 2011). These carotenoids have been largely ignored in the context of agro-food and health and are the major abundant dietary carotenoids (Mapelli-Brahm et al., 2017). Violaxanthin is also present in apricot (Katayama et al., 1971). Polyphenols found in apricot include catechin, hydroxycinnamic acids (chlorogenic, neochlorogenic acids, $p$-coumaric, Table 1), epicatechin, epigallocatechin, kaempferol-3-rutinoside, quercetin-3-glucosides, and rutin (Table 1, Dragovic-Uzelac et al., 2007; Campbell et al., 2013). Recently, some other minor phenolic compounds were identified, such as hyperoside, narcissin, and naringenin (Di Vaio et al., 2019). Among anthocyanins, cyanidin-3-O-rutinoside (the most abundant, Table 1), cyanidin-3-O-glucoside and peonidin-3-O-rutinoside have been detected in some accessions (Bureau et al., 2009). pCoumaric acid has strong antioxidant potential and besides, it has been identified in apricot fruit, and its amounts and those of coumaroyl hexose are very low (Dragovic-Uzelac et al., 2005). Chlorogenic (caffeoyl quinic acid) is an abundant polyphenol in apricot (Dragovic-Uzelac et al., 2005). Caffeic acid has also been detected (Campbell et al., 2013).

About 200 different volatile compounds have been described in apricots (El Hadi et al., 2013). The main volatile phytochemicals include aldehydes, alcohols, ketones, esters, terpenes, and hydrocarbons. The most abundant are hexanal, (E)-2-hexenal, linalool, 1-hexanol, ethyl octanoate, and hexyl acetate (Table 2). These volatiles are recognized as major contributors to apricot scent (Aubert and Chanforan, 2007; González-Agüero et al., 2009). The aldehydes hexanal and (E)-2-hexenal display the higher concentrations and have been shown to decrease during ripening. Terpene compounds (i.e., linalool) and alcohols (i.e. 1hexanol) are less abundant than aldehydes, and decrease with ripening (Table 2, González-Agüero et al., 2009).

\section{Plums}

Plums may be good sources of natural antioxidants. Plums contain high amounts of polyphenolic compounds, which include anthocyanins, hydroxycinnamates, flavan 3-ols and flavonols. The most common and predominant are chlorogenic acid, neochlorogenic acid, catechin, epicatechin, and quercetin-3-rutinoside (Rutin) (Table 1, Kim et al., 2003; Tomas-Barberán et al., 2001). However, differences in contents were found in different species of plum, such as Prunus domestica, Prunus salicina, and Prunus cerasifera (Moscatello et al., 2019). Other flavonol glycosides such as cyanidin-3-glucoside and cyanidin-3-galactoside have also been described. Anthocyanins are found in fresh plums predominantly as rutinoside derivatives, such as cyaniding-3-rutinoside (keracyanin, Table 2), cyanidin-3-glucoside (kuromanin), and peonidin 3-rutinoside (Raynal et al., 1989; Kim et al., 2003). It is important to mention that anthocyanins have not been detected in yellow plums (Kim et al., 2003). Although plums are not the richest source of carotenes, they contain neoxanthin, lutein, and violaxanthin (Biehler et al., 2011).

Thirty-six different volatile compounds have been identified in Japanese plums (Lozano et al., 2009). In general, they are grouped in esters and lactones, with hexanal, butyl acetate, (E)-2hexenal, butyl butyrate, hexyl acetate, linalool (2,6-dimethyl-2,7octadien-6-ol), $\gamma$-decalactone and $\gamma$-dodecalactone being the most abundant. Hexanal, provides the plum-like aroma (Gómez et al., 1993 and references therein). Levels of some representative volatiles are shown in Table 2 .

Not only the number of identified volatiles is shorter in plum than in apricots and peach, but also, they have been found in lower amounts (Gómez et al., 1993). Particularly, while the concentrations of $\mathrm{C}_{6}$ compounds (hexanal, (E)-2-hexenal, hexanol, (Z)-3-hexen-1-ol), and their esters are higher in plums than in apricots, apricots are richer in aromatic compounds (Table 2). Hydrocarbons were more frequent in plums than in apricots (Gómez et al., 1993).

\section{Almond Kernels}

Bitter almonds have important quantities (3-9\%) of amygdalin, which releases hydrocyanic acid and benzaldehyde upon enzymatic hydrolysis (Wirthensohn et al., 2008) and are mainly used in the production of flavor extracts. In turn, sweet almond is consumed as a whole nut, blanched or peeled in the form of a healthy snack or ingredient (Yada et al., 2011). Polyphenols contribute to color and to the moderate astringency. The most predominant polyphenols are proanthocyanidins, hydrolysable tannins, and flavonoids. The amount of some representative polyphenols in different $P$. armeniaca cultivars is presented in Table $\mathbf{1}$.

Almond major proanthocyanidins include epicatechin and catechin. Epiafzelechin is a minor proanthocyanidin. Tannins render gallotannins and ellagitannins after hydrolysis. More than 25 flavonoids have been described in almonds including anthocyanidins (derived from the hydrolysis of proanthocyanidins), flavan-3-ols (catechin, dihydrokaempferol, dihydroquercetin, epicatechin, epicatechin gallate, epicatechin glycoside, and gallocatechin gallate), flavan-3-ols (dihydrokaempferol, catechin, and epicatechin), flavonols (isorhamnetin, kaempferol, quercetin and their 3-O-glucosides, galactosides, and rutinosides), and flavanones (eriodictyol, naringenin, and 7-O-glucosides), and a biflavone. Flavonols are the most abundant flavonoid class in almond. Phenolic acids, lignans, isoflavones, and stilbenes are less represented polyphenols (Bolling, 2017). Almonds are rich in unsaturated lipids and in $\alpha$-, $\delta$-, $\beta$-, and $\gamma$ tocopherol (Franklin et al., 2017).

Volatiles isolated from almond include more than 20 compounds such as alkylfuranones, n-alkanes, cyclopentadiene and aromatic compounds, such as benzaldehyde, methyl phenol, 
benzyl alcohol, and some alkylbenzenes. Among the dominant components is benzaldehyde, which has been reported as a predominant volatile of kernel oils from the botanical family Rosaceae and is associated with a marzipan-like flavor, benzyl alcohol, and methyl benzene (Table 2). Octane, n-tridecane, ntetradecane, and hexadecane are the n-alkanes identified (Picuric-Jovanovic and Milovanovic, 1993).

On the other hand, almond skin is a source of bioactive polyphenols and thus of antioxidant activity. About 30 phenolic compounds have been identified which include flavan-3-ols (the more abundant comprising proanthocyanidins, catechin, epicatechin), flavonol glycosides (kaempferol-3-O-rutinoside, kaempferol-3-O-glucoside, isorhamnetin-3-O-rutinoside, isorhamnetin-3-O-glucoside, and quercetin-3-O-glucoside), hydroxybenzoic acids ( $p$-hydroxybenzoic acid, vanillic acid, and protocatechuic acid) and aldehydes (protocatechuic aldehyde), flavonol aglycones (kaempferol, quercetin, and isorhamnetin), flavanone glycosides (naringenin-7-O-glucoside and eriodictyol-7-O-glucoside), flavanone aglycones (naringenin and eriodictyol), hydroxycinnamic acids (trans- $p$-coumaric acid and chlorogenic acid), and dihydroflavonol aglycones (dihydroquercetin) (Table 1, Garrido et al., 2008).

\section{Sweet Cherries}

Cherries are rich in phenolic compounds, mainly represented by hydroxycinnamates, anthocyanins, flavan-3-ols and flavonols

(Table 1, Gonçalves et al., 2004).

The main anthocyanins in cherries are cyaniding-3-glucoside, cyanidin-3-rutinoside (Gonçalves et al., 2007; Goulas et al., 2015). While pelargonidin-3-O-rutinoside (Mozetic et al., 2002) and peonidin-3-O-rutinoside occur at low levels in some cultivars (Gonçalves et al., 2007), they were not detected in others (Goulas et al., 2015). Cyanidin-3-rutinoside represents $90 \%$ of the total anthocyanin content (Usenik et al., 2008). Sweet cherries are a good source of phenolic acids such as hydroxycinnamic acid derivatives (neochlorogenic acid, p-coumaroyl quinic acid and chlorogenic acid) (Liu et al., 2011) Flavonoids detected in sweet cherries include catechin, epicatechin, rutin, quercetin, quercetin-3-rutinoside, quercetin derivative, and kaempferol derivative (Chockchaisawasdee et al., 2016). Fingerprinting conducted by Goulas et al. (2015) revealed that in sweet cherries the levels of hydroxycinnamates are higher than those of flavonoids. Fresh sweet cherry fruit volatiles include alcohols, aldehydes, ketones, hydrocarbons/terpenes and esters, with aldehydes, alcohols, and esters being the most represented (Table 2). Hexanal, (E)2-hexenal, benzaldehyde, (E)-2-hexen-1-o1, ethyl acetate, and hexanoic acid ethyl ester give the typical sweet cherry scent.

\section{PRE- AND POSTHARVEST TREATMENTS AFFECTING THE PHYTOCHEMICAL BIOSYNTHESIS AND COMPOSITION IN STONE FRUIT}

Apart from the studies related to transcription factors involved in the regulation of secondary organic compounds in stone fruit, studies on peach, cherry, and apricot reveal that the composition and concentration of the different phytochemicals vary among the cultivars (Tomas-Barberan et al., 2001; Gil et al., 2002; Cantín et al., 2009; Di Matteo et al., 2017). However, still very few studies have investigated the profiles and content of phenolic and volatiles in several cultivars (Di Vaio et al., 2008; Wang et al., 2009; Di Vaio et al., 2015; Di Matteo et al., 2017). Moreover, the molecular basis for the differences in phytochemical content among varieties has not been investigated in detail yet.

In addition, other factors, like the rootstock (Remorini et al., 2008), the water supply (Tavarini et al., 2011), the growing region, climatic conditions, plant density, nutrient management and agronomic practices (Dragovic-Uzelac et al., 2007; Buendía et al., 2008; Álvarez-Fernández et al., 2011), the state of maturation and various factors in the postharvest stage, and handling (Gil et al., 2002; Dragovic-Uzelac et al., 2007; Tavarini et al., 2011; Scordino et al., 2012; Dabbou et al., 2016; Jia et al., 2009) influence fruit quality and the content of secondary organic compounds and thus consumers acceptance (Minas et al., 2018). Regarding the geographic growing regions, the effect of altitude in the skin pigmentation of peach fruit has been studied. Orchards from higher altitudes showed higher content of total phenols, flavonoids, carotenoids, and anthocyanins in comparison with those grown at lower altitudes (Karagiannis et al., 2016). The content of other metabolites such as quercetin-3-glucoside in apricot does not vary with the ripening stage (Campbell et al., 2013); however, it has been shown that fruit:leaf ratio has an impact on the phytochemical composition of the fruit. For example, fruit thinning, the adjustment of the fruit number of the tree, during pit hardening of apricot improved the phytochemical (total phenolics) content in some cultivars (Roussos et al., 2011). Other practices such as nitrogenous fertilization also affects the phenolic, flavonoid, and anthocyanin contents as it is the case of peach fruit (Vashisth et al., 2017). Depending on the fruit species and the phytochemical considered, the level of secondary organic metabolites might vary upon developmental and ripening stage. For example, in apricots, while the content of some phenolic compounds was constant during ripening, the amounts of others varied (Dragovic-Uzelac et al., 2007). In addition, the content of carotenoids increased during ripening in three different cultivars tested at two different locations (Dragovic-Uzelac et al., 2007). In consequence, the harvest time might affect the health-beneficial properties of the fruit. In this respect, research conducted in plums shows the evolution of the content of different secondary organic metabolites such as carotenoids, total phenolics, anthocyanins during development and ripening on tree of different cultivars (Díaz-Mula et al., 2008; Jiang et al., 2019). Nevertheless, these works showed contradictory results i.e., while Díaz-Mula et al. (2008) described a decrease in phenolics over development of plum; Jiang et al. (2019) showed an increase of phenolic compounds. Later, Moscatello et al. (2019) studying the evolution of sugars, organic acids, and bioactive compounds over development, ripening and overripening, showed that metabolite content is influenced by dilution effects due to the expansion of the fruit. Thus, while phenolics exhibit a net decrease when expressed in terms of fresh or dry weight basis, the net content per fruit 
increases. Therefore, during plum fruit growth and development there is a net increase in the amount of these bioactive compounds due to synthesis.

On the other hand, the application of different postharvest abiotic stress in horticultural crops has proven to be a simple and effective technology to induce the accumulation of secondary metabolites with a wide range of applications in dietary supplements, functional foods, pharmaceutical markets, cosmetics and agrochemicals. Thus, the use and/or generation of wounds, ultraviolet light, modified atmospheres and phytohormones (ethylene and methyl jasmonate, etc.) in fresh fruits and vegetables induces the accumulation of antioxidants (Cisneros-Zevallos, 2003; Jacobo-Velázquez and CisnerosZevallos, 2012). More recently, emerging technologies such as ultrasound have been used to generate abiotic stress to induce the accumulation of phenolic compounds (Jacobo-Velázquez and Cisneros- Zevallos, 2018). Particularly in peaches, it was found that the effectiveness of the treatment with UV-B in the modulation of the concentration of phenolic compounds and the expression of the genes involved in the synthesis of phenylpropanoids was genotype-dependent (Scattino et al., 2014; Zhao et al., 2017). UV-A and UV-B treatment increased the content of flavonoids, ascorbate, and cyanidin-3-O-glucoside, and thus, it increased the antioxidant activity of treated peach (Sgherri et al., 2015). In line with these results, bagging also affects the accumulation of nutraceutic compounds. Yellow paper prevents the penetration of blue and UV light resulting in poor coloration of the skin (Liu et al., 2015). In contrast, white non-woven polypropylene allows the accumulation of anthocyanin in the skin. Liu et al. (2015) showed increased expression of the TFs $P p M Y B$ 10.1, PpMYB 10.2, and $P p M Y B 10.3$ and their partners $P p b H L H 3$ and $P p W D 40-1$ in peach covered with white non-woven polypropylene with respect to fruit covered with yellow paper. Enhanced expression of regulatory genes resulted in higher levels of $P p C H S, P p D F R$, and $P$ PUFGT in peach bagged using non-woven polypropylene. UV-C treatment during the postharvest storage is also effective in inducing anthocyanin accumulation in cold stored peach (Zhou et al., 2020). In sweet cherries, UV-C applied to fruit after harvest and then cold stored also resulted in an increase in anthocyanins, flavonoids, and total phenolics (Michailidis et al., 2019). Temperature during the postharvest also affects total phenolics and anthocyanin levels. While cold storage at $1-2^{\circ} \mathrm{C}$ decreases total phenolic content (with neochlorogenic and p-coumaroylquinic acids been the most abundant) in four cultivars of sweet cherries harvested at ripe stage, storage at $15 \pm 5^{\circ} \mathrm{C}$ increases them. In contrast, anthocyanin increased up to fivefold at both temperatures in both ripe and in partially ripe cherries (Gonçalves et al., 2004). On the other hand, after 15 days of fruit storage at $1^{\circ} \mathrm{C}$, Esti et al. (2002), also testing two cultivars harvested at commercial maturity indicated a considerable decrease in anthocyanin content. With respect to apricot, heat stress was effective to raise the antioxidant capacity (Madrau et al., 2009).

Preharvest and postharvest oxalic acid (OA) treatment has been successfully applied to stone fruits to increase their nutraceutical properties. In sweet cherries, treatments with OA during development (Martinez-Espla et al., 2014; Martinez-Espla et al., 2019) or during the postharvest followed by 50-day cold storage (Valero et al., 2011) were effective to induce total phenolics, anthocyanins, and antioxidant activity. In peach, OA application 15 days before harvest improved total flavonoids, phenolics, and antioxidant activity in cold stored peach for 28 days (Razavi and Hajiloub, 2016). In addition, in plum (Prunus salicina Lindl. 'Black Splendor'), OA applied as a foliar spray during fruit development successfully increased total phenolics and total antioxidant activity in harvested fruit and after cold storage ( 35 days at $2^{\circ} \mathrm{C}+1$ day at $20^{\circ} \mathrm{C}$, Serrano et al., 2018).

Postharvest treatment on several Prunus fruit with methylcyclopropene (1-MCP), an inhibithor of ethylene perception (Sisler and Serek, 1997), provoked a delay of color development (Valero et al., 2005). Application of 1-MCP resulted in a negative effect on the expression of genes involved in the biosythentic pathway of carotenoids (Marty et al., 2005; Ziliotto et al., 2008) and anthocyanins (Niu et al., 2017) thus, supporting the regulatory role of ethylene in the accumulation of carotenoids and anthocyanins in this species.

\section{FUTURE PERSPECTIVES FOR IMPROVING TYPE AND LEVELS OF SECONDARY PHYTOCHEMICALS IN STONE FRUIT}

Despite the well-known beneficial effects of fruits and vegetables in human health, consumption is still low. Therefore, great efforts should be made to increase the level of health promoting compounds in plant foods by both molecular and non-molecular methods. During the last years, important advances with regard the regulation of secondary metabolism, together with the coordination with primary metabolism, have been achieved in model species such as arabidopsis and tomato. Modification of the expression of individual TFs modifies the levels of enzymes involved not only in secondary but also in primary metabolism suggesting supercoordinated gene expression networks between primary and secondary metabolisms (Aharoni and Galili, 2011). In this respect, it has been proposed that the manipulation of primary metabolism (source of precursors) is a promissory strategy to alter secondary metabolite content (Pott et al., 2019).

In stone fruit, even though in the recent years there has been an increase in genetic (genetic linkage maps and markers associated to quality traits) and omics (genome sequences, transcriptomes, metabolomes, proteomes and volatilomes) resources (Aranzana et al., 2019), there is still limited knowledge about the main factors regulating the accumulation of secondary organic metabolites. Upcoming research of pre- and posthavrest treatements on phytochemical composition should also consider the differences in development and ripening stages of the fruit. More studies should be performed in the future because, as stated in the present review, there is large evidence that stone fruits are rich in secondary organic metabolites, and thus, they may become biofactories of health promoting compounds. The manipulation of primary metabolism to alter secondary metabolite content (Pott et al., 2019) is also a strategy to be considered in stone fruits. 
Besides, several studies have highlighted the importance of epigenetic influence in plant ontogenesis, flowering time, heterosis, and fruit ripening process in other species. Much of the information regarding genetic control and epigenetic regulation has been obtained in tomato. The main actors (TF) involved in the transition from fruit growth to ripening have been identified (Giovannoni, 2007), and epigenetic regulation of the targets of these master regulators has also been described in tomato (Giovannoni et al., 2017). Regarding postharvest, epigenetic regulation of the senescence process has been explored in tomato, strawberry, and citrus (Farinati et al., 2017). In comparison, in stone fruits information is scarce, but it is starting to emerge (Fresnedo-Ramírez et al., 2017; Ma et al., 2018). Future studies are really needed and will help in the elucidation of epigenomic dynamics and the epigenetic mechanisms in stone fruit, which may also control secondary organic metabolite production and its relationship with stress condition exposures.

Finally, apart from a deeper knowledge about the molecular mechanisms related to the regulation of the levels of secondary organic compounds in stone fruits, the phytochemical content of the large number of different stone fruit varieties should be

\section{REFERENCES}

Abbas, F., Ke, Y., Yu, R., Yue, Y., Amanullah, S., Jahangir, M. M., et al. (2017). Volatile terpenoids: multiple functions, biosynthesis, modulation and manipulation by genetic engineering. Planta 246, 803-816. doi: 10.1007/ s00425-017-2749-x

Abdulrazzak, N., Pollet, B., Ehlting, J., et al. (2006). A coumaroyl-3'-ester hydroxylase insertion mutant reveals the existence of nonredundant metahydroxylation pathways and essential roles for phenolic precursors in cell expansion and plant growth. Plant Physiol. 140, 30-48. doi: 10.1104/ pp.105.069690

Adami, M., De Franceschi, P., Brandi, F., Liverani, A., Giovannini, D., et al. (2013). Identifying a carotenoid cleavage dioxygenase (ccd4) gene controlling yellow/ white fruit flesh color of peach. Plant Mol. Biol. Rep. 31, 1166-1175. doi: 10.1007/s11105-013-0628-6

Aharoni, A., and Galili, G. (2011). Metabolic engineering of the plant primarysecondary metabolism interface. Curr. Op. Biotechnol. 22, 239-244. doi: 10.1016/j.copbio.2010.11.004

Álvarez-Fernández, A., Melgar, J. C., Abadía, J., and Abadía, A. (2011). Effects of moderate and severe iron deficiency chlorosis on fruit yield, appearance and composition in pear (Pyrus communis L.) and peach (Prunus persica (L.) batsch). Environ. Exp. Bot. 71, 280-286. doi: 10.1016/j.envexpbot.2010.12.012

Andersen, O. M., and Markham, K. R. (2005). Flavonoids: Chemistry, Biochemistry and Applications. 1st ed (Boca Raton, FL, USA: CRC Press), 1-1256.

Aranzana, M. J., Decroocq, V., Dirlewanger, E., et al. (2019). Prunus genetics and applications after de novo genome sequencing: achievements and prospects. Hortic. Res. 6, 58. doi: 10.1038/s41438-019-0140-8

Aseervatham, G. S. B., Suryakala, U., Doulethunisha,, Sundaram, S., Bose, P. C., and Sivasudha, T. (2016). Expression pattern of NMDA receptors reveals antiepileptic potential of apigenin 8-C-glucoside and chlorogenic acid in pilocarpine induced epileptic mice. Biomed. Pharmacother. 82, 54-64. doi: 10.1016/j.biopha.2016.04.066

Aubert, C., and Chanforan, C. (2007). Postharvest changes in physicochemical properties and volatile constituents of apricot (Prunus armeniaca L.). Characterization of 28 cultivars. J. Agric. Food Chem. 55, 3074-3082. doi: $10.1021 / \mathrm{jf} 063476 \mathrm{w}$

Aubert, C., Bony, P., Chalot, G., Landry, P., and Lurol, S. (2014). Effects of Storage Temperature, Storage Duration, and Subsequent Ripening on the Physicochemical deeply characterized. Besides, the molecular mechanisms underlying the differences in phytochemical contents among varieties of the same stone fruit species should be identified. These results could be used in breeding programs to enhance nutritional value of stone fruits, which may aid, along with improved pre- and postharvest handling strategies, in the enlargement of the health promoting compounds of stone fruit for consumers' benefits in the years to come.

\section{AUTHOR CONTRIBUTIONS}

All authors contributed to the article and approved the submitted version. However, MD and ML had a major role in the design and writing of the article.

\section{FUNDING}

$M L$ and $M D$ acknowledge funding from CONICET and ANPCYT.

Characteristics, Volatile Compounds, and Phytochemicals of Western Red Nectarine (Prunus persica L. Batsch). J. Agric. Food. Chem. 62, 4707-4724.

Belhadj, F., Somrani, I., Aissaoui, N., Boussaid, M., and Nejib Marzouki, M. (2016). Bioactive compounds contents, antioxidant and antimicrobial activities during ripening of Prunus persica L. varieties from the North West of Tunisia. Food Chem. 204, 29-36. doi: 10.1016/j.foodchem.2016.02.111

Berryman, C. E., Preston, A. G., Karmally, W., Deckelbaum, R. J., and KrisEtherton, P. M. (2011). Effects of almond consumption on the reduction of LDL-cholesterol: a discussion of potential mechanisms and future research directions. Nutr. Rev. 69, 171-185. doi: 10.1111/j.1753-4887.2011.00383.x

Bhandarkar, N. S., Brown, L., and Panchal, S. K. (2019a). Chlorogenic acid attenuates high-carbohydrate, high-fat diet-induced cardiovascular, liver, and metabolic changes in rats. Ntr. Res. 62, 68-78. doi: 10.1016/j.nutres. 2018.11.002

Bhandarkar, N. S., Mouatt, P., Brown, L., and Panchal, S. K. (2019b). Green coffee ameliorates components of diet-induced metabolic syndrome in rats. J. Funct. Foods 57, 141-149. doi: 10.1016/j.jff.2019.04.003

Biehler, E., Alkerwi, A., Hoffmann, L., Krause, E., Guillaume, M., Lair, M.-L., et al. (2011). Contribution of violaxanthin, neoxanthin, phytoene and phytofluene to total carotenoid intake: Assessment in Luxembourg. J. Food Compos. Anal. 25, 56-65. doi: 10.1016/j.jfca.2011.07.005

Block, A. K., Vaughan, M. M., Schmelz, E. A., and Christensen, S. A. (2019). Biosynthesis and function of terpenoid defense compounds in maize (Zea mays). Planta 249, 21-30. doi: 10.1007/s00425-018-2999-2

Bolling, B. W. (2017). Almond Polyphenols: Methods of Analysis, Contribution to Food Quality, and Health Promotion. Compr. Rev. Food Sci. Food Saf. 73, 106 115. doi: $10.1111 / 1541-4337.12260$

Bowles, D., Lim, E. K., Poppenberger, B., and Vaistij, F. E. (2006). Glycosyltransferases of lipophilic small molecules. Ann. Rev. Plant Biol. 57, 567-597. doi: 10.1146/annurev.arplant.57.032905.105429

Brandi, F., Bar, E., Mourgues, F., Horváth, G., Turcsi, E., Giuliano, G., et al. (2011). Study of 'Redhaven' peach and its white-fleshed mutant suggests a key role of CCD4 carotenoid dioxygenase in carotenoid and norisoprenoid volatile metabolism. BMC Plant Biol. 11, 24-37. doi: 10.1186/1471-2229-11-24

Bruhn, C. M., Feldman, N., Garlitz, C., Harwood, J., Ivans, E., Marshall, M., et al. (1991). Consumer perceptions of quality: Apricots, cantaloupes, peaches, pears, strawberries, and tomatoes. J. Food Qual. 14, 187. doi: 10.1111/j.17454557.1991.tb00060.x 
Buendía, B., Allende, A., Nicolás, E., et al. (2008). Effect of regulated deficit irrigation and crop load on the antioxidant compounds of peaches. J. Agric. Food Chem. 56, 3601-3608. doi: 10.1021/jf800190f

Bureau, S., Renard, C. M. G. C., Reich, M., Ginies, C., and Audergon, J. M. (2009). Change in anthocyanin concentrations in red apricot fruits during ripening. LWT Food Sci. Technol. 42, 372-377. doi: 10.1016/j.lwt.2008.03.010

Campbell, O. E., and Padilla-Zakour, O. I. (2013). Phenolic and carotenoid composition of canned peaches (Prunus persica) and apricots (Prunus armeniaca) as affected by variety and peeling. Food Res. Int. 54, 448-455. doi: 10.1016/j.foodres.2013.07.016

Campbell, O. E., Merwin, I. A., and Padilla-Zakour, O. I. (2013). Characterization and the effect of maturity at harvest on the phenolic and carotenoid content of northeast USA apricot (Prunus armeniaca) varieties. J. Agric. Food Chem. 61, 12700-12710. doi: 10.1021/jf403644r

Cantín, C. M., Moreno, M. A., and Gogorcena, Y. (2009). Evaluation of the antioxidant capacity, phenolic compounds, and vitamin $\mathrm{C}$ content of different peach and nectarine [Prunus persica (L.) batsch] breeding progenies. J. Agric. Food Chem. 57, 4586-4592. doi: 10.1021/jf900385a

Cao, S., Liang, M., Shi, L., Shao, J., Song, C., Bian, K., et al. (2017). Accumulation of carotenoids and expression of carotenogenic genes in peach fruit. Food Chem. 214, 137-146. doi: 10.1016/j.foodchem.2016.07.085

Cevallos-Casals, B. A., Byrne, D., Okie, W. E. R., and Cisneros-Zeballos, L. (2006). Selecting new peach and plum genotypes rich in phenolic compounds and enhanced functional properties. Food Chem. 96, 273-280. doi: 10.1016/ j.foodchem.2005.02.032

Chai, Q., Liu, W., Wang, L., Yang, C., Wang, Y., Fang, J., et al. (2012). Volatiles of plums evaluated by HS-SPME with GC-MS at the germplasm level. Food Chem. 130, 432-440.

Chen, Y., Al-Ghamdi, A. A., Elshikh, M. S., Shah, M. H., Al-Dosary, M. A., and Abbasi, A. M. (2020). Phytochemical profiling, antioxidant and HepG2 cancer cells' antiproliferation potential in the kernels of apricot cultivars. Saudi J. Biol. Sci. 27, 163-172. doi: 10.1016/j.sjbs.2019.06.013

Cheng, J., Wei, G., Zhou, H., Gu, C., Vimolmangkang, S., Liao, L., et al. (2014). Unraveling the mechanism underlying the glycosylation and methylation of anthocyanins in peach. Plant Physiol. 166, 1044-1058. doi: 10.1104/ pp.114.246876

Cheng, Y., Liu, L., Yuan, C., and Guan, J. (2015). Molecular characterization of ethylene-regulated anthocyanin biosynthesis in plums during fruit ripening. Plant Mol. Biol. Rep. 34, 777-785. doi: 10.1007/s11105-015-0963-x

Chockchaisawasdee, S., Golding, J. B., Vuong, Q. V., Papoutsis, K., and Stathopoulos, C. E. (2016). Sweet cherry: Composition, postharvest preservation, processing and trends for its future use. Trends Food Sci. Technol. 55, 72e83. doi: 10.1016/j.tifs.2016.07.002

Chun, O. K., Chung, S. J., and Song, W. O. (2007). Estimated dietary flavonoid intake and major food sources of U.S. adults. J. Nutr. 137, 1244-1252. doi: $10.1093 /$ jn $/ 137.5 .1244$

Cisneros-Zevallos, L. (2003). The use of controlled postharvest abiotic stresses as a tool for enhancing the nutraceutical content and adding-value of fresh fruits and vegetables. J. Food Sci. 68, 1560-1565. doi: 10.1111/j.1365-2621.2003.tb12291.x

Cuevas, F. J, Moreno-Rojas, J. M, Arroyo, F., Daza, A., and Ruiz-Moreno, M. J. (2016). Effect of management (organic vs conventional) on volatile profiles of six plum cultivars (Prunus salicina Lindl.). A chemometric approach for varietal classification and determination of potential markers. Food Chem. 199, 479-484.

Dabbou, S., Lussiana, C., Maatallah, S., et al. (2016). Changes in biochemical compounds in flesh and peel from Prunus persica fruits grown in Tunisia during two maturation stages. Plant Physiol. Biochem. 100, 1-11. doi: 10.1016/ j.plaphy.2015.12.015

Dabbou, S., Maatallah, S., Castagna, A., Guizani, M., Sghaeir, W., Hajlaoui, H., et al. (2017). Carotenoids, Phenolic Profile, Mineral Content and Antioxidant Properties in Flesh and Peel of Prunus persica Fruits during Two Maturation Stages. Plant Foods Hum. Nutr. 72, 103-110. doi: 10.1007/s11130-016-0585-y

Derail, C., Hofmann, T., and Schieberle, P. (1999). Differences in Key Odorants of Handmade Juice of Yellow-Flesh Peaches (Prunus persica L.) Induced by the Workup Procedure. J. Agric. Food Chem. 47, 4742-4745. doi: 10.1021/ jf990459g

Di Matteo, A., Russo, R., Graziani, G., Ritieni, A., and Di Vaio, C. (2017). Characterization of autochthonous sweet cherry cultivars (Prunus avium L.) of southern Italy for fruit quality, bioactive compounds and antioxidant activity. J. Sci. Food Agric. 97, 2782-2794. doi: 10.1002/jsfa.8106

Di Vaio, C., Graziani, G., Marra, L., Cascone, A., and Ritieni, A. (2008). Antioxidant capacities, carotenoids and polyphenols evaluation of fresh and refrigerated peach and nectarine cultivars from Italy. Eur. Food Res. Technol. 227, 1225-1231. doi: 10.1007/s00217-008-0840-z

Di Vaio, C., Marallo, N., Graziani, G., Ritieni, A., and Di Matteo, A. (2015). Evaluation of fruit quality, bioactive compounds and total antioxidant activity of flat peach cultivars. J. Sci. Food Agric. 95, 2124-2131. doi: 10.1002/jsfa.6929

Di Vaio, C., Cirillo, C., Pannico, A., Graziani, G., Ritieni, A., and Famiani, F. (2019). Bioactive compounds and fruit quality traits of Vesuvian apricot cultivars (Prunus armeniaca L.) and use of skin cover colour as a harvesting index. Aust. J. Crop Sci. 13, 2022-2029. doi: 10.21475/ajcs.19.13.12.p2024

Díaz-Mula, H. M., Zapata, P. J., Guillén, F., Castillo, S., Martínez-Romero, D., Valero, D., et al. (2008). Changes in physicochemical and nutritive parameters and bioactive compounds during development and on-tree ripening of eight plum cultivars: a comparative study. J. Sci. Food Agric. 88, 2499-2507. doi: $10.1002 /$ jsfa. 3370

Dicenta, F., Martínez-Gómez, P., Grané, N., Martín, M. L., León, A., Cánovas, J. A., et al. (2002). Relationship between cyanogenic compounds in kernels, leaves, and roots of sweet and bitter kernelled almonds. J. Agric. Food Chem. 50, 21492152. doi: $10.1021 / \mathrm{jf} 0113070$

Dixon, R. A., and Steele, C. L. (1999). Flavonoids and isoflavonoids: a gold mine for metabolic engineering. Trends Plant Sci. 4, 394-400.

Dragovic-Uzelac, V., Delonga, K., Levaj, B., Djakovic, S., and Pospisil, J. (2005). Phenolic profiles of raw apricots, pumpkins, and their purees in the evaluation of apricot nectar and jam authenticity. J. Agric. Food Chem. 53, 4836-4842. doi: $10.1021 / \mathrm{jf} 040494+$

Dragovic-Uzelac, V., Levaj, B., Mrkic, V., Bursac, D., and Boras, M. (2007). The content of polyphenols and carotenoids in three apricot cultivars depending on stage of maturity and geographical region. Food Chem. 102, 966-975. doi: 10.1016/j.foodchem.2006.04.001

Drochioiu, G., Arsene, C., Murariu, M., and Oniscu, C. (2008). Analysis of cyanogens with resorcinol and picrate. Food Chem. Toxicol. 46, 3540-3545. doi: $10.1016 /$ j.fct.2008.09.005

Dubos, C., Le Gourrierec, J., Baudry, A., Huep, G., Lanet, E., Debeaujon, I., et al. (2008). MYBL2 is a new regulator of flavonoid biosynthesis in Arabidopsis thaliana. Plant J. 55, 940-953. doi: 10.1111/j.1365-313X.2008.03564.x

Dudareva, N., Klempien, A., Muhlemann, J. K., and Kaplan, I. (2013). Biosynthesis, function and metabolic engineering of plant volatile organic compounds. New Phytol. 198, 16-32. doi: 10.1111/nph.12145

Eduardo, I., Chietera, G., Bassi, D., Rossini, L., and Vecchietti, A. (2010). Identification of key odor volatile compounds in the essential oil of nine peach accessions. J. Sci. Food Agricult. 90, 1146-1154. doi: 10.1002/jsfa.3932

El Hadi, M. A. M., Zhang, F.-J., Wu, F.-F., Zhou, C.-H., and Tao, J. (2013). Advances in Fruit Aroma Volatile Research. Molecules 18, 8200-8229. doi: 10.3390/molecules 18078200

El-Sharkawy, I., Liang, D., and Xu, K. (2015). Transcriptome analysis of an apple (Malus $\times$ domestica) yellow fruit somatic mutation identifies a gene network module highly associated with anthocyanin and epigenetic regulation. J. Exp. Bot. 22, 7359-7376. doi: 10.1093/jxb/erv433

Elvira-Torales, L. I., García-Alonso, J., and Periago-Castón, M. J. (2019). Nutritional Importance of Carotenoids and Their Effect on Liver Health. Antioxidants 8, 229. doi: 10.3390/antiox8070229

Erdogan-Orhan, I., and Kartal, M. (2011). Insights into research on phytochemistry and biological activities of Prunus armeniaca L. (apricot). Food Res. Int. 44, 1238-1243. doi: 10.1016/j.foodres.2010.11.014

Esti, M., Cinquanta, L., Sinesio, F., Moneta, E., and Di Matteo, M. (2002). Physicochemical and sensory fruit characteristics of two sweet cherry cultivars after cool storage. Food Chem. 76, 399-405. doi: 10.1016/S03088146(01)00231-X

Falchi, R., Vendramin, E., Zanon, L., Scalabrin, S., Cipriani, G., Verde, I., et al. (2013). Three distinct mutational mechanisms acting on a single gene underpin the origin of yellow flesh in peach. Plant J. 76, 175-187. doi: 10.1111/tpj.12283

Fang, Z.-Z., Zhou, D.-R., Ye, X.-F., Jiang, C.-C., and Pan, S.-L. (2016). Identification of Candidate Anthocyanin-Related Genes by Transcriptomic Analysis of 'Furongli' Plum (Prunus salicina Lindl.) during Fruit Ripening Using RNA-Seq. Front. Plant Sci. 7, 1338. doi: 10.3389/fpls.2016.01338 
Farinati, S., Rasori, A., Varotto, S., and Bonghi, C. (2017). Rosaceae Fruit Development, Ripening and Post-harvest: An Epigenetic Perspective. Front. Plant Sci. 8:1247. doi: 10.3389/fpls.2017.01247

Franklin, L. M., Chapman, D. M., King, E. S., Mau, M., Huang, G., and Mitchell, A. E. (2017). Chemical and Sensory Characterization of Oxidative Changes in Roasted Almonds Undergoing Accelerated Shelf Life. J. Agric. Food Chem. 65 (12), 2549-2563. doi: 10.1021/acs.jafc.6b05357

Fresnedo-Ramírez, J., Chan, H. M., Parfitt, D. E., Crisosto, C. H., and Gradziel, T. M. (2017). Genome-wide DNA-(de) methylation is associated with Noninfectious Bud-failure exhibition in Almond (Prunus dulcis [Mill.] D.A.Webb). Sci. Rep. 7, 42686. doi: 10.1038/srep42686

Fukuda, T., Ito, H., Mukainaka, T., Tokuda, H., Nishino, B., and Yoshida, T. (2003). Anti-tumor Promoting Effect of Glycosides from Prunus persica Seeds. Biol. Pharm. Bull. 26, 271-273. doi: 10.1248/bpb.26.271

García-Gómez, B. E., Salazar, J. A., Dondini, L., Martínez-Gómez, P., and Ruiz, D. (2019). Identification of QTLs linked to fruit quality traits in apricot (Prunus armeniaca L.) and biological validation through gene expression analysis using qPCR. Mol. Breed. 39, 28. doi: 10.1007/s11032-018-0926-7

Garrido, I., Monagas, M., Gómez-Cordovés, C., and Bartolomé, B. (2008). Polyphenols and Antioxidant Properties of Almond Skins: Influence of Industrial Processing. J. Food Chem. 73, C106-C115. doi: 10.1111/j.1750-3841.2007.00637.x

Gasparotto, J., Somensi, N., Bortolin, R. C., Moresco, K. Z., Girardi, C. S., Klafke, K., et al. (2014). Effects of different products of peach (Prunus persica L. Batsch) from a variety developed in southern Brazil on oxidative stress and inflammatory parameters in vitro and ex vivo. J. Clin. Biochem. Nutr. 55, 110-119. doi: 10.3164/ jcbn.13-97

Gil, M. I., Tomas-Barberan, F. A., Hess-Pierce, B., and Kader, A. A. (2002). Antioxidant capacities, phenolic compounds, carotenoids, and vitamin C contents of nectarine, peach, and plum cultivars from California. J. Agric. Food Chem. 50, 4976-4982. doi: 10.1021/jf020136b

Giovannoni, J., Nguyen, C., Ampofo, B., Zhong, S., and Fei, Z. (2017). The Epigenome and Transcriptional Dynamics of Fruit Ripening. Annu. Rev. Plant Biol. 68, 61-84. doi: 10.1146/annurev-arplant-042916-040906

Giovannoni, J. J. (2007). Fruit ripening mutants yield insights into ripening control. Curr. Opin. Plant Biol. 10, 283-289. doi: 10.1016/j.pbi.2007.04.008

Gleadow, R. M., and Møller, B. L. (2014). Cyanogenic glycosides: synthesis, physiology, and phenotypic plasticity. Ann. Rev. Plant Biol. 65, 155-185. doi: 10.1146/annurev-arplant-050213-040027

Goff, S. A., and Klee, H. J. (2006). Plant Volatile Compounds: Sensory Cues for Health and Nutritional Value? Science 311, 815-819. doi: 10.1126/science.1112614

Gómez, E., Ledbetter, C. A., and Hartsell, P. L. (1993). Volatile Compounds in Apricot, Plum, and Their Interspecific Hybrids. J. Agric. Food Chem. 41, 16691676. doi: 10.1021/jf00034a029

Gonçalves, B., Landbo, A.-K., Knudsen, D., Silva, A. P., Moutinho-Pereira, J., Rosa, E., et al. (2004). Effect of ripeness and postharvest storage on the phenolic profiles of cherries (Prunus avium L.). J. Agric. Food Chem. 52, 523-530. doi: $10.1021 /$ jf030595s

Gonçalves, B., Silva, A. P., Moutinho-Pereira, J., Bacelar, E., Rosa, E., and Meyer, A. S. (2007). Effect of ripeness and postharvest storage on the evolution of colour and anthocyanins in cherries (Prunus avium L.). Food Chem. 103, 976984. doi: 10.1016/j.foodchem.2006.08.039

Gonda, I., Davidovich-Rikanati, R., Bar, E., Lev, S., Jhirad, P., Meshulam, Y., et al. (2018). Differential metabolism of L-phenylalanine in the formation of aromatic volatiles in melon (Cucumis melo L.) fruit. Phytochemistry 148, 122-131. doi: 10.1016/j.phytochem.2017.12.018

González-Agüero, M., Troncoso, S., Gudenschwager, O., Campos-Vargas, R., Moya-León, M. A., and Defilippi, B. G. (2009). Differential expression levels of aroma-related genes during ripening of apricot (Prunus armeniaca L.). Plant Physiol. Biochem. 47, 435-440. doi: 10.1016/j.plaphy.2009.01.002

Goulas, V., Minas, I. S., Kourdoulos, P. M., Lazaridou, A., Molassiotis, A. N., Gerothanassis, I. P., et al. (2015). 1H NMR metabolic fingerprinting to probe temporal postharvest changes on qualitative attributes and phytochemical profile of sweet cherry fruit. Front. Plant Sci. 6, 959. doi: 10.3389/fpls.2015.00959

Grotewold, E., and Davis, K. (2008). Trafficking and sequestration of anthocyanins. Nat. Prod. Commun. 3, 1251-1258. doi: 10.1177/1934578X0800300806

Grotewold, E. (2004). The challenges of moving chemicals within and out of cells: insights into the transport of plant natural products. Planta 219, 906-909. doi: $10.1007 /$ s00425-004-1336-0
Grotewold, E. (2006). The Genetics and Biochemistry of Floral Pigments. Annu. Rev. Plant Biol. 57, 761-780.

Grubb, C. D., and Abel, S. (2006). Glucosinolate metabolism and its control. Trends Plant Sci. 11, 89-100. doi: 10.1016/j.tplants.2005.12.006

Grundy, M. M., Lapsley, K., and Ellis, P. R. (2016). A review of the impact of processing on nutrient bioaccessibility and digestion of almonds. Int. J. Food Sci. Technol. 51, 1937-1946. doi: 10.1111/ijfs.13192

Guichard, E., and Souty, M. (1988). Comparison of the relative quantities of aroma compounds found in fresh apricot (Prunusarmeniaca) from six different varieties. Z. Lebensm Unters Forch. 186, 301-307. doi: 10.1007/ BF01027031

Hayaloglu, AA, and Demir, N. (2015). Phenolic Compounds, Volatiles, and Sensory Characteristics of Twelve Sweet Cherry (Prunus avium L.) Cultivars Grown in Turkey. J. Food Sci. 81, C7-C18.

He, Q., Yao, K., Jia, D., Fan, H., Liao, X., and Shi, B. (2009). Determination of total catechins in tea extracts by HPLC and spectrophotometry. Nat. Prod. Res. 23, 93-100. doi: 10.1080/14786410801886682

Heller, W., Forkmann, G., Britsch, L., and Griseback, H. (1985). Enzymatic reduction of (+)-dihydroflavonols to flavan-3,4-cis-diols with flower extracts from Matthiola incana and its role in anthocyanin biosynthesis. Planta 165, 284-287. doi: 10.1007/BF00395052

Hernandez, J., Heine, G., Irani, N. G., Feller, A., Kim, M.-G., et al. (2004). Mechanisms of cooperation between MYB and HLH transcription factors in the regulation of anthocyanin pigmentation. J. Biol. Chem. 279, 48205-48213. doi: 10.1074/jbc.M407845200

Hichri, I., Barrieu, F., Bogs, J., Kappel, C., Delrot, S., and Lauvergeat, V. (2011). Recent advances in the transcriptional regulation of the flavonoid biosynthetic pathway. J. Exp. Bot. 62, 2465-2483. doi: 10.1093/jxb/erq442

Hoffmann, L., Maury, S., Martz, F., et al. (2003). Purification, cloning, and properties of an acyltransferase controlling shikimate and quinate ester intermediates in phenylpropanoid metabolism. J. Biol. Chem. 278, 95-103. doi: 10.1074/jbc.M209362200

Horvat, R. J., Chapman, G. W., Robertson, J. A., Meredith, F. I., Scorza, R., et al. (1990). Comparison of the volatile compounds from several commercial peach cultivars. J. Agric. Food Chem. 38, 234-237. doi: 10.1021/jf00091a051

Hou, X., Rivers, J., León, P., Mcquinn, R. P., and Pogson, B. J. (2016). Synthesis and function of apocarotenoid signals in plants. Trends Plant Sci. 21, 792-803. doi: 10.1016/j.tplants.2016.06.001

Huang, Z., Wanga, Q., Xia, L., Hui, J., Li, J., Feng, Y., et al. (2019). Preliminarily exploring of the association between sugars and anthocyanin accumulation in apricot fruit during ripening. Sci. Hortic. 248, 112-117. doi: 10.1016/ j.scienta.2019.01.012

Hull, S., Re, R., Chambers, L., Echaniz, A., and Wickham, M. S. (2015). A midmorning snack of almonds generates satiety and appropriate adjustment of subsequent food intake in healthy women. Eur. J. Nutr. 54, 803-810. doi: 10.1007/s00394-014-0759-z

Hung, H. C., Joshipura, K. J., Jiang, R., Hu, F. B., Hunter, D., Smith-Warner, S. A., et al. (2004). Fruit and vegetable intake and risk of major chronic disease. J. Natl. Cancer Inst. 96, 1577-1584. doi: 10.1093/jnci/djh296

Jacobo-Velázquez, D. A., and Cisneros-Zevallos, L. (2012). An Alternative Use of Horticultural Crops: Stressed Plants as Biofactories of Bioactive Phenolic Compounds. Agriculture 2, 259-271. doi: 10.3390/agriculture2030259

Jacobo-Velázquez, D. A., and Cisneros-Zevallos, L. (2018). An alternative use of horticultural crops: stressed plants as biofactories of bioactive glucosinolate and phenolic compounds. Acta Hortic. 1194, 947-952. doi: 10.17660/ ActaHortic.2018.1194.134. ISHS 2018.

Jaswal, V., Palanivelu, J., and C., R. (2018). Effects of the Gut microbiota on Amygdalin and its use as an anti-cancer therapy: Substantial review on the key components involved in altering dose efficacy and toxicity. Biochem. Biophys. Rep. 14, 125-132.

Jeong, S. T., Goto-Yamamoto, N., Kobayashi, S., and Esaka, M. (2004). Effects of plant hormones and shading on the accumulation of anthocyanins and the expression of anthocyanin biosynthetic genes in grape berry skins. Plant Sci. 167, 247-252. doi: 10.1016/j.plantsci.2004.03.021

Jez, J. M., and Noel, J. P. (2000). Mechanism of chalcone synthase. pKa of the catalytic cysteine and the role of the conserved histidine in a plant polyketide synthase. J. Biol. Chem. 275, 39640-39646. doi: 10.1074/ jbc.M008569200 
Jia, H.-J., Araki, A., and Okamoto, G. (2005). Influence of fruit bagging on aroma volatiles and skin coloration of 'Hakuho' peach (Prunus persica Batsch). Postharv. Biol. Technol. 35, 61-68. doi: 10.1016/j.postharvbio. 2004.06.004

Jiang, C. C., Fang, Z. Z., Zhou, D. R., Pan, S. L., and Ye, X. F. (2019). Changes in secondary metabolites: Organic acids and soluble sugars during the development of plum fruit cv. 'Furongli' (Prunus salicina Lindl). J. Sci. Food Agric. 99, 1010-1019. doi: 10.1002/jsfa.9265

Jin, W, Wang, H, Li, M, Wang, J, Yang, Y, Zhang, X, et al. (2016). The R2R3 MYB transcription factor PavMYB10.1 involves in anthocyanin biosynthesis and determines fruit skin colour in sweet cherry (Prunus avium L.). Plant Biotechnol. J. 14 (11), 2120-2133. doi: 10.1111/pbi.12568

Kamil, A., and Chen, C. Y. (2012). Health benefits of almonds beyond cholesterol reduction. J. Agric. Food. Chem. 60, 6694-6702. doi: 10.1021/jf2044795

Karagiannis, E., Tanou, G., Samiotaki, M., Michailidis, M., Diamantidis, G., Minas, I. S., et al. (2016). Comparative Physiological and Proteomic Analysis Reveal Distinct Regulation of Peach Skin Quality Traits by Altitude. Front. Plant Sci. 7, 1689. doi: $10.3389 /$ fpls.2016.01689

Katayama, T., Nakayama, T. O. M., Lee, T. H., and Chichester, C. O. (1971). Carotenoid transformations in ripening apricots and peaches. J. Food Sci. 36, 804-806. doi: 10.1111/j.1365-2621.1971.tb03311.x

Katayama, S., Ogawa, H., and Nakamura, S. (2011). Apricot Carotenoids Possess Potent Anti-amyloidogenic Activity. Vitro. J. Agric. Food Chem. 5923, 1269112696

Kim, D. O., Chun, K., Kim, Y. J., Moon, H., and Lee, C. Y. (2003a). Quantification of polyphenolics and their antioxidant capacity in fresh plums. J. Agricult. Food Chem. 51, 6509-6515. doi: 10.1021/jf0343074

Kim, D.-O., Jeong, S. W., and Lee, C. Y. (2003b). Antioxidant capacity of phenolic phytochemicals from various cultivars of plums. Food Chem. 81, 321-326. doi: 10.1016/S0308-8146(02)00423-5

Kim, Y.-Y., Koo, B. S., Gong, D. J., Lee, Y. C., Ko, J. H., and Kim, C. H. (2003c). Comparative effect of Prunus persica L. BATSCH-water extract and tacrine (9amino-1,2,3,4-tetrahydroacridine hydrochloride) on concentration of extracellular acetylcholine in the rat hippocampus. J. Ethnopharmacol. 87, 149-154. doi: 10.1016/S0378-8741(03)00106-5

Kim, H. J., Park, K. K., Chung, W. Y., Lee, S. K., and Kim, K. R. (2017). Protective Effect of White-fleshed Peach (Prunus persica (L.) Batsch) on Chronic Nicotine-induced Toxicity. J. Cancer Prev. 22, 22-32. doi: 10.15430/ JCP.2017.22.1.22

Kim, B., Kim, K. W., Lee, S., Jo, C., Lee, K., Ham, I., et al. (2019). EndotheliumDependent Vasorelaxant Effect of Prunus Persica Branch on Isolated Rat Thoracic Aorta. Nutrients 11, 1816. doi: 10.3390/nu11081816

Koes, R., Verweij, W., and Quattrocchio, F. (2005). Flavonoids: a colorful model for the regulation and evolution of biochemical pathways. Trends Plant Sci. 10, 236-242. doi: 10.1016/j.tplants.2005.03.002

Koprivica, M. R., Trifković, J. D., Dramićanin, A. M., Gašić, U. M., Fotirić Akšić, M. M., and MilojkovićOpsenica, D. M. (2018). Determination of the phenolic profile of peach (Prunus persica L.) kernels using UHPLC-LTQ OrbiTrap MS/ MS technique. Eur. Food Res. Technol. 244, 2051-2064. doi: 10.1007/s00217018-3116-2

Kuhn, B. M., Geisler, M., Bigler, L., and Ringli, C. (2011). Flavonols accumulate asymmetrically and affect auxin transport in Arabidopsis. Plant Physiol. 156, 585-595. doi: 10.1104/pp.111.175976

Lee, C. Y., Kagan, V., Jaworski, A. W., and Brown, S. K. (1990). Enzymic browning in relation to phenolic compounds and polyphenoloxidase activity among various peach cultivars. J. Agric. Food Chem. 38, 99-101. doi: 10.1021/ jf00091a019

Li, L., and Yuan, H. (2013). Chromoplast biogenesis and carotenoid accumulation. Arch. Biochem. Biophys. 539, 102-109. doi: 10.1016/j.abb.2013.07.002

Li, D., Wang, P., Luo, Y., Zhao, M., and Chen, F. (2017). Health benefits of anthocyanins and molecular mechanisms: Update from recent decade. Crit. Rev. Food Sci. Nutr. 57, 8, 1729-1741. doi: 10.1080/10408398.2015.1030064

Liang, N., and Kitts, D. D. (2016). Role of chlorogenic acids in controlling oxidative and inflammatory stress conditions. Nutrients 8, 16. doi: 10.3390/ nu8010016

Liang, M. H., Zhu, J., and Jiang, J. G. (2018). Carotenoids biosynthesis and cleavage related genes from bacteria to plants. Crit. Rev. Food Sci. Nutr. 58 (14), 2314-2333. doi: 10.1080/10408398.2017.1322552
Lin-Wang, K., Bolitho, K., Grafton, K., Kortstee, A., Karunairetnam, S., McGhie, T. K., et al. (2010). An R2R3 MYB transcription factor associated with regulation of the anthocyanin biosynthetic pathway in Rosaceae. BMC Plant Biol. 10, 50. doi: 10.1186/1471-2229-10-50

Liu, Y., Liu, X., Zhong, F., Tian, R., Zhang, K., Zhang, X., et al. (2011). Comparative study of phenolic compounds and antioxidant activity in different species of cherries. J. Food Sci. 76, 633-638. doi: 10.1111/j.1750-3841.2011.02150.x

Liu, Y., Shen, X., Zhao, K., Ben, Y., Guo, X., Zhang, X., et al. (2013). Expression Analysis of Anthocyanin Biosynthetic Genes in Different Colored Sweet Cherries (Prunus avium L.) During Fruit Development. J. Plant Growth Regul. 32, 901-907. doi: 10.1007/s00344-013-9355-3

Liu, Y. J., Zhou, C. Y., Qiu, C. H., Lu, X. M., and Wang, Y. T. (2013). Chlorogenic acid induced apoptosis and inhibition of proliferation in human acute promyelocytic leukemia HL-60 cells. Mol. Med. Rep. 8, 1106-1110. doi: $10.3892 / \mathrm{mmr} .2013 .1652$

Liu, H., Cao, J., and Jiang, W. (2015). Evaluation and comparison of vitamin C, phenolic compounds, antioxidant properties and metal chelating activity of pulp and peel from selected peach cultivars. LWT Food Sci. Technol. 63, 10421048. doi: 10.1016/j.lwt.2015.04.052

Liu, T., Song, S., Yuan, Y. B., Wu, D. J., Chen, M. J., Sun, Q. N., et al. (2015). Improved peach peel color development by fruit bagging. Enhanced expression of anthocyanin biosynthetic and regulatory genes using white non-woven polypropylene as replacement for yellow paper. Sci. Hortic. 184, 142-148. doi: 10.1016/j.scienta.2015.01.003

Llorente, B., D'Andrea, L., Ruiz-Sola, M. A., Botterweg, E., Pulido, P., Andilla, J., et al. (2016). Tomato fruit carotenoid biosynthesis is adjusted to actual ripening progression by a light-dependent mechanism. Plant J. 85, 107-119. doi: $10.1111 /$ tpj.13094

Llorente, B., Martinez-Garcia, J. F., Stange, C., and Rodriguez-Concepcion, M. (2017). Illuminating colors: regulation of carotenoid biosynthesis and accumulation by light. Cur. Op. Plant Biol. 37, 49-55. doi: 10.1016/j.pbi.2017.03.011

Lozano, M., Vidal-Aragón, M. C., Hernández, M. T., Ayuso, M. C., Bernalte, M. J., García, J., et al. (2009). Physicochemical and nutritional properties and volatile constituents of six Japanese plum (Prunus salicina Lindl.) cultivars. Eur. Food Res. Technol. 228, 403-410. doi: 10.1007/s00217-008-0946-3

Ma, K., Sun, L., Cheng, T., Pan, H., Wang, J., and Zhang, Q. (2018). Epigenetic Variance, Performing Cooperative Structure with Genetics, Is Associated with Leaf Shape Traits in Widely Distributed Populations of Ornamental Tree Prunus mume. Front. Plant Sci. 9, 41. doi: 10.3389/fpls.2018.00041

Madrau, M., Piscopo, A., Sanguinetti, A., Del Caro, A., Poiana, M., Romeo, F., et al. (2009). Effect of drying temperature on polyphenolic content and antioxidant activity of apricots. Eur. Res. Technol. 228, 441-448. doi: 10.1007/s00217-0080951-6

Maeda, H., and Dudareva, N. (2012). The Shikimate Pathway and Aromatic Amino Acid Biosynthesis in Plants. Annu. Rev. Plant Biol. 63, 73-105. doi: 10.1146/annurev-arplant-042811-105439

Manganaris, G. A., Drogoudi, P., Goulas, V., Tanou, G., Georgiadou, E. C., Pantelidis, G. E., et al. (2017). Deciphering the interplay among genotype, maturity stage and low-temperature storage on phytochemical composition and transcript levels of enzymatic antioxidants in Prunus persica fruit. Plant Physiol. Biochem. 119, 189-199.

Mapelli-Brahm, P., Corte-Real, J., Meléndez-Martínez, A. J., and Bohn, T. (2017). Bioaccessibility of phytoene and phytofluene is superior to other carotenoids from selected fruit and vegetable juices. Food Chem. 229, 304-311. doi: 10.1016/j.foodchem.2017.02.074

Markham, K. R., Gould, K. S., Winefield, C. S., Mitchell, K. A., Bloor, S. J., and Boase, M. R. (2000). Anthocyanic vacuolar inclusions-their nature and significance in flower colouration. Phytochemistry 55, 327-336. doi: 10.1016/ S0031-9422(00)00246-6

Marrs, K. A., Alfenito, M. R., Lloyd, A. M., and Walbot, V. (1995). A glutathione Stransferase involved in vacuolar transfer encoded by the maize gene Bronze-2. Nature 375, 397-400. doi: 10.1038/375397a0

Martens, S., and Mithofer, A. (2005). Flavones and flavone synthases. Phytochemistry 66, 2399-2407. doi: 10.1016/j.phytochem.2005.07.013

Martínez-Espla, A., Zapata, P. J., Valero, D., Garcia-Viguera, C., Castillo, S., and Serrano, M. (2014). Preharvest application of oxalic acid increased fruit size, bioactive compounds, and antioxidant capacity in sweet cherry cultivars (Prunus avium L.). J. Agric. Food Chem. 62, 3432-3437. doi: 10.1021/jf500224g 
Martínez-Esplá, A., Serrano, M., Martínez-Romero, D., Valero, D., and Zapata, P. J. (2019). Oxalic acid preharvest treatment increases antioxidant systems and improves plum quality at harvest and during postharvest storage. J. Sci. Food Agric. 99, 235-243. doi: 10.1002/jsfa.9165

Martini, S., Conte, A., and Tagliazucchi, D. (2017). Phenolic compounds profile and antioxidant properties of six sweet cherry (Prunus avium) cultivars. Food Res. Int. 97, 15-26.

Marty, I., Bureau, S., Sarkissian, G., Gouble, B., Audergon, J. M., and Albagnac, G. (2005). Ethylene regulation of carotenoid accumulation and carotenogenic gene expression in colour-contrasted apricot varieties (Prunus armeniaca). J. Exp. Bot. 56, 1877-1886. doi: 10.1093/jxb/eri177

Matsuba, Y., Sasaki, N., Tera, M., et al. (2010). A novel glucosylation reaction on anthocyanins catalyzed by acyl-glucose-dependent glucosyltransferase in the petals of carnation and delphinium. Plant Cell 22, 3374-3389. doi: 10.1105/ tpc.110.077487

Meng, S., Cao, J., Feng, Q., Peng, J., and Hu, Y. (2013). Roles of chlorogenic acid on regulating glucose and lipids metabolism: A review. Evid. Based. Complement. Alternat. Med. 2013, 801457. doi: 10.1155/2013/801457

Michailidis, M., Karagiannis, E., Polychroniadou, C., Tanou, G., Karamanoli, K., and Molassiotis, A. (2019). Metabolic features underlying the response of sweet cherry fruit to postharvest UV-C irradiation. Plant Physiol. Biochem. 144, 4957.

Minas, I. S., Tanou, G., and Molassiotis, A. (2018). Environmental and orchard bases of peach fruit quality. Sci. Hortic. 235, 307-322. doi: 10.1016/ j.scienta.2018.01.028

Miyahara, T., Takahashi, M., Ozeki, Y., and Sasaki, N. (2012). Isolation of an acylglucose-dependent anthocyanin 7-O-glucosyltransferase from the monocot Agapanthus africanus. J. Plant Physiol. 169, 1321-1326. doi: 10.1016/ j.jplph.2012.05.004

Miyahara, T., Sakiyama, R., Ozeki, Y., and Sasaki, N. (2013). Acyl-glucose-dependent glucosyltransferase catalyzes the final step of anthocyanin formation in Arabidopsis. J. Plant Physiol. 170, 619-624. doi: 10.1016/j.jplph.2012.12.001

Montefiori, M., Espley, R. V., Stevenson, D., et al. (2011). Identification and characterisation of F3GT1 and F3GGT1, two glycosyltransferases responsible for anthocyanin biosynthesis in red-fleshed kiwifruit (Actinidia chinensis). Plant J. 65, 106-118. doi: 10.1111/j.1365-313X.2010.04409.x

Montevecchi, G., Vasile Simone, G., Mellano, M. G., Masino, F., and Antonelli, A. (2013). Fruit sensory characterization of four Pescabivona, white-fleshed peach [Prunus persica (L.) Batsch], landraces and correlation with physical and chemical parameters. Fruits 68, 195-207. doi: 10.1051/fruits/2013067

Morishita, T., Kojima, Y., Maruta, T., Nishizawa-Yokoi, A., Yabuta, Y., and Shigeoka, S. (2009). Arabidopsis NAC transcription factor ANAC078, regulates flavonoid biosynthesis under high-light. Plant Cell Physiol. 50, 2210-2222. doi: 10.1093/pcp/pcp159

Moscatello, S., Frioni, T., Blasi, F., Proietti, S., Pollini, L., Verducci, G., et al. (2019). Changes in absolute contents of compounds affecting the taste and nutritional properties of the flesh of three plum species. Foods 8, 486. doi: 10.3390/ foods 8100486

Mozetic, B., Trebse, P., and Hribar, J. (2002). Determination and quantitation of anthocyanins and hydroxycinnamic acids in different cultivars of sweet cherries (Prunus avium L.) from Nova Gorica region (Slovenia). Food Technol. Biotechnol. 40, 207-212.

Nakajima, J., Tanaka, Y., Yamazaki, M., and Saito, K. (2001). Reaction mechanism from leucoanthocyanidin to anthocyanidin 3-glucoside, a key reaction for coloring in anthocyanin biosynthesis. J. Biol. Chem. 276, 25797-25803. doi: 10.1074/jbc.M100744200

Nakayama, T., Suzuki, H., and Nishino, T. (2003). Anthocyanin acyltransferases: specificities, mechanism, phylogenetics, and applications. J. Mol. Catal. B. Enzym. 23, 117-132. doi: 10.1016/S1381-1177(03)00078-X

Niggeweg, R., Michael, A. J., and Martin, C. (2004). Engineering plants with increased levels of the antioxidant chlorogenic acid. Nat. Biotech. 22, 746-754. doi: $10.1038 / \mathrm{nbt} 966$

Niu, J., Zhang, G., Zhang, W., Goltsev, V., Sun, S., Wang, J., et al. (2017). Anthocyanin concentration depends on the counterbalance between its synthesis and degradation in plum fruit at high temperature. Sci. Rep. 7, 7684. doi: 10.1038/s41598-017-07896-0

Nozue, M., Nishimura, M., Katou, A., Hattori, C., and Usuda, N. (1993). Characterization of intravacuolar pigmented structures in anthocyanin- containing cells of sweet potato suspension cultures. Plant Cell Physiol. 34, 803-808. doi: 10.1093/oxfordjournals.pcp.a078487

Oksana, S., Marian, B., Mahendra, R., and Bo, S. H. (2012). Plant phenolic compounds for food, pharmaceutical and cosmetics production. J. Med. Plants. Res 125, 2526-2539. doi: 10.5897/JMPR11.1695

Oliveira, A., Alexandre, E. M. C., Coelho, M., Barros, R. M., Almeida, D. P. F., and Pintado, M. (2016). Peach polyphenol and carotenoid content as affected by frozen storage and pasteurization. Food Sci. Technol. 66, 361e368. doi: 10.1016/ j.lwt.2015.10.037

Ozturk, F., Gul, M., Ates, B., Ozturk, I. C., Cetin, A., Vardi, A., et al. (2009). Protective effect of apricot (Prunus armeniaca L.) on hepatic steatosis and damage induced by carbon tetrachloride in Wistar rats. Brit. J. Nutr. 102, 17671775. doi: 10.1017/S0007114509991322

Pang, Y., Peel, G. J., Sharma, S. B., et al. (2008). A transcript profiling approach reveals an epicatechin-specific glucosyltransferase expressed in the seed coat of Medicago truncatula. Proc. Natl. Acad. Sci. U.S.A. 105, 14210-14215. doi: 10.1073/pnas.0805954105

Pelletier, M. K., Murrell, J. R., and Shiley, B. W. (1997). Characterization of flavonol synthase and leucoanthocyanidin dioxygenase genes in Arabidopsis Further evidence for differential regulation of "early" and "late" genes. Plant Physiol. 113, 1437-1445. doi: 10.1104/pp.113.4.1437

Picuric-Jovanovic, K., and Milovanovic, M. (1993). Analysis of Volatile Compounds in Almond and Plum Kernel Oils. J. Am. Oil Chem. Soc 70, 1101-1104. doi: 10.1007/BF02632149

Pietta, G., Minoggio, M., and Bramati, L. (2003). "Plant polyphenols: structure, occurance and bioactivity," in Studies in Natural Products Chemistry, vol. Vol. 28 . Ed. A.-u. Rahman (Amsterdam: Netherlands: Elsevier Science B.V). 2003.

Pino, J. A., and Quijano, C. E. (2012). Study of the volatile compounds from plum (Prunus domestica L. cv. Horvin) and estimation of their contribution to the fruit aroma. Cienc. Tecnol. Aliment. Campinas. 32, 76-83.

Pott, D. M., Osorio, S., and Vallarino, J. G. (2019). From Central to Specialized Metabolism: An Overview of Some Secondary Compounds Derived From the Primary Metabolism for Their Role in Conferring Nutritional and Organoleptic Characteristics to Fruit. Front. Plant Sci. 10, 835. doi: 10.3389/ fpls.2019.00835

Quattrocchio, F., Wing, J., van der Woude, K., Souer, E., de Vetten, N., Mol, J., et al. (1999). Molecular analysis of the anthocyanin2 gene of Petunia and its role in the evolution of flower color. Plant Cell 11, 1433-1444. doi: 10.1105/ tpc.11.8.1433

Rahim, M. A., Busatto, N., and Trainotti, L. (2014). Regulation of anthocyanin biosynthesis in peach fruits. Planta 240, 913-929. doi: 10.1007/s00425-014-2078-2

Ravaglia, D, Espley, RV, Henry-Kirk, RA, Andreotti, C, Ziosi, V, Hellens, RP, et al. (2013). Transcriptional regulation of flavonoid biosynthesis in nectarine (Prunus persica) by a set of R2R3 MYB transcription factors. BMC Plant Biol. 13, 68 .

Raynal, J., Moutounet, M., and Souquet, J.-M. (1989). Intervention of phenolic compounds in plum technology. 1. changes during drying. J. Agric. Food Chem. 37, 1046-1050. doi: 10.1021/jf00088a050

Razavi, F., and Hajiloub, J. (2016). Enhancement of postharvest nutritional quality and antioxidant capacity of peach fruits by preharvest oxalic acid treatment. Sci. Hortic. 200, 95-101. doi: 10.1016/j.scienta.2016.01.011

Reddy, A. R., Britsch, L., Salamini, F., Saedler, H., and Rohde, W. (1987). The A1 (anthocyanin-1) locus in Zea mays encodes dihydroquercitin reductase. Plant Sci. 52, 7-13. doi: 10.1016/0168-9452(87)90098-7

Remorini, D., Tavarini, S., Degl'Innocenti, E., et al. (2008). Effect of rootstocks and harvesting time on the nutritional quality of peel and flesh of peach fruits. Food Chem. 110, 361-367. doi: 10.1016/j.foodchem.2008.02.011

Riboli, E., and Norat, T. (2003). Epidemiologic evidence of the protective effect of fruit and vegetables on cancer risk. Am. J. Clin. Nutr. 78, 559S-569S. doi: 10.1093/ajcn/78.3.559S

Roussos, P. A., Sefferou, V., Denaxa, N.-K., Tsantili, E., and Stathis, V. (2011). Apricot (Prunus armeniaca L.) fruit quality attributes and phytochemicals under different crop load. Sci. Hortic. 129, 472-478. doi: 10.1016/j.scienta.2011.04.021

Ruiz, D., Egea, J., Gil, M .I., and Tomás-Barberán, F. A. (2005). Characterization and quantitation of phenolic compounds in new apricot (Prunus armeniaca L.) varieties. J. Agric. Food Chem. 53 (24), 9544-9552. doi: 10.1021/jf051539p

Saito, K., Yonekura-Sakakibara, K., Nakabayashi, R., Higashi, Y., Yamazaki, M., Tohge, T., et al. (2013). The flavonoid biosynthetic pathway in Arabidopsis: 
structural and genetic diversity. Plant Physiol. Biochem. 72, 21-34. doi: 10.1016/j.plaphy.2013.02.001

Sánchez, G., Besada, C., Badenes, M. L., Monforte, A. J., and Granell, A. (2012). A Non-Targeted Approach Unravels the Volatile Network in Peach Fruit. PloS One 7, e38992. doi: 10.1371/journal.pone.0038992

Sánchez, G., Martínez, J., Romeu, J., García, J., Monforte, A .J., Badenes, M. L., et al. (2014). The peach volatilome modularity is reflected at the genetic and environmental response levels in a QTL mapping population. BMC Plant Biol. 14, 137.

Sánchez-Pérez, R., Jørgensen, K., Olsen, C. E., Dicenta, F., and Møller, B. L. (2008). Bitterness in almonds. Plant Physiol. 146, 1040-1052. doi: 10.1104/ pp.107.112979

Sánchez-Pérez, R., Pavan, S., Mazzeo, R., Moldovan, C., Aiese Cigliano, R., Cueto, D., et al. (2019). Mutation of a bHLH transcription factor allowed almond domestication. Science 364, 1095-1098. doi: 10.1126/science.aav8197

Santana-Gálvez, J., Cisneros-Zevallos, L., and Jacobo-Velázquez, D. A. (2017). Chlorogenic Acid: Recent Advances on Its Dual Role as a Food Additive and a Nutraceutical against Metabolic Syndrome. Molecules 22, 358. doi: 10.3390/ molecules 22030358

Sasaki, K., Alamed, J., Weiss, J., Villeneuve, P., López Giraldo, L. J., Lecomte, J., et al. (2010). Relationship between the physical properties of chlorogenic acid esters and their ability to inhibit lipid oxidation in oil-in-water emulsions. Food Chem. 118, 830-835. doi: 10.1016/j.foodchem.2009.05.070

Saslowsky, D., and Winkel, B. (2001). Localization of flavonoid enzymes in Arabidopsis roots. Plant J. 27, 37-48, S. doi: 10.1046/j.1365-313x.2001.01073.x

Saslowsky, D. E., Warek, U., and Winkel, B. S. (2005). Nuclear localization of flavonoid enzymes in Arabidopsis. J. Biol. Chem. 280, 23735-23740. doi: 10.1074/jbc.M413506200

Scattino, C., Castagna, A., Neugart, S., et al. (2014). Post-harvest UV-B irradiation induces changes of phenol contents and corresponding biosynthetic gene expression in peaches and nectarines. Food Chem. 163, 51-60. doi: 10.1016/ j.foodchem.2014.04.077

Schmitzer, V., Slatnar, A., Mikulic-Petkovsek, M., Veberic, R., Krska, B., and Stampar, F. (2011). Comparative study of primary and secondary metabolites in apricot (Prunus armeniaca L.) cultivars. J. Sci. Food Agric. 91, 860-866.

Scordino, M., Sabatino, L., Muratore, A., et al. (2012). Phenolic characterization of Sicilian yellow flesh peach (Prunus persica L.) cultivars at different ripening stages. J. Food Qual. 35, 255-262. doi: 10.1111/j.1745-4557.2012.00452.x

Serra, A. T., Duarte, R. O., Bronze, M. R., and Duarte, C. M. M. (2011). Identification of bioactive response in traditional cherries from Portugal. Food Chem. 125, 318-325. doi: 10.1016/j.foodchem.2010.07.088

Serrano, M., Marnez-Esplá, A., Giménez, M. J., Valero, D., Zapata, P. J., Guillén, F., et al. (2018). Preharvest application of oxalic acid improves antioxidant systems in plums. Acta Hortic. 1194, 19-24. doi: 10.17660/ActaHortic.2018.1194.4. ISHS 2018.

Sgherri, C., Scattino, C., Pinzino, C., Tonutti, P., and Ranieri, A. M. (2015). Ultraviolet-B radiation applied to detached peach fruit: A study of free radical generation by EPR spin trapping. Plant Physiol. Biochem. 96, 124e131. doi: 10.1016/j.plaphy.2015.07.031

Shen, X., Zhao, K., Liu, L., Zhang, K., Yuan, H., Liao, X., et al. (2014). A Role for PacMYBA in ABA-Regulated Anthocyanin Biosynthesis in Red-Colored Sweet Cherry cv. Hong Deng (Prunus avium L.). Plant Cell Physiol. 55, 862-880. doi: 10.1093/pcp/pcu013

Silva, R. F., and Poganik, L. (2020). Polyphenols from Food and Natural Products: Neuroprotection and Safety. Antioxidants 6, 61. doi: 10.3390/antiox9010061

Sisler, E. C., and Serek, M. (1997). Inhibitors of ethylene responses in plants at the receptor level: recent developments. Physiol. Plantarum. 100, 577-582. doi: 10.1111/j.1399-3054.1997.tb03063.x

Springob, K., Nakajima, J.-I., Yamazaki, M., and Saito, K. (2003). Recent advances in the biosynthesis and accumulation of anthocyanins. Nat. Prod. Rep. 20, 288303. doi: 10.1039/b109542k

Stanley, L., and Yuan, Y.-W. (2019). Transcriptional Regulation of Carotenoid Biosynthesis in Plants: So Many Regulators, So Little Consensus. Front. Plant Sci. 10:1017. doi: 10.3389/fpls.2019.01017

Starkevič, P., Paukštytė, J., Kazanavičiūtè, V., Denkovskienè, E., Stanys, V., Bendokas, V., et al. (2015). Expression and Anthocyanin BiosynthesisModulating Potential of Sweet Cherry (Prunus avium L.) MYB10 and bHLH Genes. PloS One 10 (5), e0126991. doi: 10.1371/journal.pone.0126991
Steyn, W. J., Wand, S. J., Jacobs, G., Rosecrance, R. C., and Roberts, S. C. (2009). Evidence for a photoprotective function of low-temperature induced anthocyanin accumulation in apple and pear peel. Physiol. Plant 136, 461472. doi: 10.1111/j.1399-3054.2009.01246.x

Stöckigt, J., and Zenk, H. (1974). Enzymatic synthesis of chlorogenic acid from caffeoyl coenzyme A and quinic acid. FEBS Lett. 42, 131-134. doi: 10.1016/ 0014-5793(74)80769-6

Sun, T., Yuan, H., Cao, H., Yazdani, M., Tadmor, Y., and Li, L. (2018). Carotenoid Metabolism in Plants: The Role of Plastids. Mol. Plant 11, 58-74. doi: 10.1016/ j.molp.2017.09.010

Suzuki, A., Yamamoto, N., Jokura, H., Yamamoto, M., Fujii, A., Tokimitsu, I., et al. (2006). Chlorogenic acid attenuates hypertension and improves endothelial function in spontaneously hypertensive rats. J. Hypertens. 24, 1065-1073. doi: 10.1097/01.hjh.0000226196.67052.c0

Swain, E., Li, C. P., and Poulton, J. E. (1992). Development of the potential for cyanogenesis in maturing black cherry (Prunus serotina) fruits. Plant Physiol. 98, 1423-1428. doi: 10.1104/pp.98.4.1423

Takos, A. M., Jaffé, F. W., Jacob, S. R., Bogs, J., Robinson, S. P., and Walker, A. R. (2006). Light-induced expression of a MYB gene regulates anthocyanin biosynthesis in red apples. Plant Physiol. 142 (3), 1216-1232. doi: 10.1104/pp.106.088104

Tanaka, Y., Sasaki, N., and Ohmiya, A. (2008). Biosynthesis of plant pigments: anthocyanins, betalains and carotenoids. Plant J. 54, 733-749. doi: 10.1111/ j.1365-313X.2008.03447.x

Tarkowská, D., and Strnad, M. (2018). Isoprenoid-derived plant signaling molecules: biosynthesis and biological importance. Planta 247, 1051-1066. doi: $10.1007 / \mathrm{s} 00425-018-2878-\mathrm{x}$

Tavarini, S., Gil, M. I., Tomás-Barberán, F. A., Buendia, B., Remorini, D., Massai, R., et al. (2011). Effects of water stress and rootstocks on fruit phenolic composition and physical/chemical quality in Suncrest peach. Ann. Appl. Biol. 158, 226-233. doi: $10.1111 / j .1744-7348.2010 .00457 . x$

Thodberg, S., Del Cueto, J., Mazzeo, R., Pavan, S., Lotti, C., Dicenta, F., et al. (2018). Elucidation of the Amygdalin Pathway Reveals the Metabolic Basis of Bitter and Sweet Almonds (Prunus dulcis). Plant Physiol. 178, 1096-1111. doi: 10.1104/pp.18.00922

Tholl, D. (2015). "Biosynthesis and biological functions of terpenoids in plants," in Biotechnology of Isoprenoids. Advances in Biochemical Engineering/ Biotechnology, vol. vol 148148 . Eds. J. Schrader and J. Bohlmann (Cham: Springer), 63-106.

Tohge, T., Yonekura-Sakakibara, H., Niida, R., Watanabe-Takahashi, A., and Saito, K. (2007). Phytochemical genomics in Arabidopsis thaliana: a case study for functional identification of flavonoid biosynthesis genes. Pure App. Chem. 79, 811-823. doi: 10.1351/pac200779040811

Tohge, T., Nishiyama, Y., Hirai, M. Y., et al. (2005). Functional genomics by integrated analysis of metabolome and transcriptome of Arabidopsis plants over-expressing an MYB transcription factor. Plant J. 42, 218-235. doi: 10.1111/j.1365-313X.2005.02371.x

Tomas-Barberan, F. A., Gil, M. I., Cremin, P., Waterhouse, A. L., Hess-Pierce, B., and Kader, A. A. (2001). HPLC-DAD-ESIMS analysis of phenolic compounds in nectarines, peaches, and plums. J. Agric. Food Chem. 49, 4748-4760. doi: $10.1021 /$ jf0104681

Tuan, P. A., Bai, S., Yaegaki, H., Tamura, T., Hihara, S., Moriguchi, T., et al. (2015). The crucial role of PpMYB10.1 in anthocyanin accumulation in peach and relationships between its allelic type and skin color phenotype. BMC Plant Biol. 15, 280. doi: 10.1186/s12870-015-0664-5

Tzin, V., and Galili, G. (2010). New Insights into the Shikimate and Aromatic Amino Acids Biosynthesis Pathways in Plants. Mol. Plant 6, 956-972.

Usenik, V., Fabcic, J., and Stampar, F. (2008). Sugars, organic acids, phenolic composition and antioxidant activity of sweet cherry (Prunus avium L.). Food Chem. 107, 185e192. doi: 10.1016/j.foodchem.2007.08.004

Valero, D., Guillén, F., Valverde, J. M., Martínez-Romero, D., Castillo, S., and Serrano, M. (2005). 1-MCP use on Prunus spp. To maintain fruit quality and to extend shelf life during storage: a comparative study. Acta Hortic. 682, 933940. doi: 10.17660/ActaHortic.2005.682.121

Valero, D., Diaz-Mula, H. M., Zapata, P. J., Castillo, S., Guillen, F., MartinezRomero, D., et al. (2011). Postharvest treatments with salicylic acid, acetylsalicylic acid or oxalic acid delayed ripening and enhanced bioactive compounds and antioxidant capacity in sweet cherry. J. Agric. Food Chem. 59, 5483-5489. doi: 10.1021/jf200873j 
Vashisth, T., Olmstead, M. A., Olmstead, J., and Colquhoun, T. A. (2017). Effects of Nitrogen Fertilization on Subtropical Peach Fruit Quality: Organic Acids, Phytochemical Content, and Total Antioxidant Capacity. J. Amer. Soc. Hortic. Sci. 142 (5), 393-404. doi: 10.21273/JASHS04011

Vavoura, M. V., Badeka, A. V., Kontakos, S., and Kontominas, M. G. (2015). Characterization of Four Popular Sweet Cherry Cultivars Grown in Greece by Volatile Compound and Physicochemical Data Analysis and Sensory Evaluation. Molecules 20, 1922-1940.

Venter, A., Joubert, E., and de Beer, D. (2013). Characterisation of Phenolic Compounds in South African Plum Fruits (Prunus salicina Lindl.) using HPLC Coupled with Diode-Array, Fluorescence, Mass Spectrometry and On-Line Antioxidant Detection. Molecules 18, 5072-5090. doi: 10.3390/ molecules 18055072

Verde, I., Abbott, A. G., Scalabrin, S., et al. (2013). The high-quality draft genome of peach (Prunus persica) identifies unique patterns of genetic diversity, domestication and genome evolution. Nat. Genet. 45, 487-494. doi: 10.1038/ ng. 2586

Visai, C., and Vanoli, M. (1997). Volatile compound production during growth and ripening of peaches and nectarines. Sci. Horticult. 70, 15-24. doi: 10.1016/ S0304-4238(97)00032-0

Vizzotto, M., Cisneros-Zevallos, L., Byrne, D., Ramming, D. W., and Okie, W. R. (2007). Large variation found in the phytochemical and antioxidant activity of peach and plum germplasm. J. Am. Soc Horticult. Sci. 132, 1-7. doi: 10.21273/ JASHS.132.3.334

Vogt, T. (2010). Phenylpropanoid Biosynthesis. Mol. Plant 1, 2-20.

Walker, R. P., and Famiani, F. (2018). Organic acids in fruits: metabolism, functions and contents. Hortic. Rev. 45, 371-430. doi: 10.1002/9781119431077.ch8

Wang, Y., Yang, C., Li, S., Yang, L., Wang, Y., et al. (2009). Volatile characteristics of 50 peaches and nectarines evaluated by HP-SPME with GC-MS. Food Chem. 116, 356-364. doi: 10.1016/j.foodchem.2009.02.004

Wang, L., Zhao, S., Gu, C., Zhou, Y., Zhou, H., Ma, J., et al. (2013). Deep RNA-Seq uncovers the peach transcriptome landscape. Plant Mol. Biol. 83, 365-377. doi: 10.1007/s11103-013-0093-5

Waterman, P. G. (1998). "Chemical taxonomy of alkaloids," in Alkaloids: Biochemistry, Ecology, and Medicinal Applications. Eds. MF Roberts and M. Wink (Boston, MA: Springer US), 87-107. doi: 10.1007/978-1-4757-2905-4_4

Weng, C. J., and Yen, G. C. (2012). Chemopreventive effects of dietary phytochemicals against cancer invasion and metastasis: Phenolic acids, monophenol, polyphenol, and their derivatives. Cancer Treat Rev. 38, 76-87. doi: $10.1016 /$ j.ctrv.2011.03.001

WHO Technical Report Series (2003). Diet, nutrition and the prevention of chronic diseases. Report of a Joint FAO/WHO Expert Consultation (Geneva: World Health Organization). No. 916.

Winkel-Shirley, B. (2001). Flavonoid biosynthesis. A colorful model for genetics, biochemistry, cell biology, and biotechnology. Plant Physiol. 126, 485-493. doi: 10.1104/pp.126.2.485

Winkel-Shirley, B. (1999). Evidence of enzyme complexes in the phenylpropanoid and flavonoid pathways. Physiol. Plant 107, 142-149. doi: 10.1034/j.13993054.1999.100119.x

Wirthensohn, M. G., Chin, W. L., Franks, T. K., Baldock, G., Ford, C. M., and Sedgley, M. (2008). Characterising the flavour phenotypes of almond (Prunus dulcis Mill.) kernels. J. Horticult. Sci. Biotechnol. 83, 462-468. doi: 10.1080/ 14620316.2008.11512407

Wu, H., Shi, J., Xue, S. J., Kakuda, Y., Wang, D., Jiang, Y. M., et al. (2011). Essential oil extracted from peach (Prunus persica) kernel and its physicochemical and antioxidant properties. LWT Food Sci. Technol. 44, 2032-2039. doi: 10.1016/ j.lwt.2011.05.012

Xi, W., Feng, J., Liu, Y., Zhang, S., and Zhao, G. (2019). The R2R3-MYB transcription factor PaMYB10 is involved in anthocyanin biosynthesis in apricots and determines red blushed skin. BMC. Plant Biol. 19, 287. doi: 10.1186/s12870-019-1898-4

Xie, D., Sharma, S., Paiva, N., Ferreira, D., and Dixon, R. (2003). Role of anthocyanidin reductase, encoded by BANYULS in plant flavonoid biosynthesis. Science 299, 396-399. doi: 10.1126/science.1078540

Yada, S., Lapsley, K., and Huang, G. (2011). A review of composition studies of cultivated almonds: Macronutrients and micronutrients. J. Food Compos. Anal. 24, 469-480. doi: 10.1016/j.jfca.2011.01.007
Yamaguchi, T., Yamamoto, K., and Asano, Y. (2014). Identification and characterization of CYP79D16 and CYP71AN24 catalyzing the first and second steps in L-phenylalanine-derived cyanogenic glycoside biosynthesis in the Japanese apricot, Prunus mume Sieb. et Zucc. Plant Mol. Biol. 86, 215223. doi: $10.1007 / \mathrm{s} 11103-014-0225-6$

Yazaki, K., Arimura, G.-I., and Ohnishi, T. (2017). 'Hidden' Terpenoids in Plants: Their Biosynthesis, Localization and Ecological Roles. Plant Cell Physiol. 58, 1615-1621. doi: 10.1093/pcp/pcx123

Yonekura-Sakakibara, K., Nakayama, T., Yamazaki, M., and Saito, K. (2009). Modification and Stabilization of Anthocyanins. In: Anthocaynins: Biosynthesis, Functions, and Applications. Eds. K. Gould, K. Davis and C. Winefield (New York: Springer), 169-190.

Yurt, B., and Celik, I. (2011). Hepatoprotective effect and antioxidant role of sun, sulphited-dried apricot (Prunus armeniaca L.) and its kernel against ethanolinduced oxidative stress in rats. Food Chem. Toxicol. 49, 508-513.

Zaghdoudi, K., Pontvianne, S., Framboisier, X., Achard, M., Kudaibergenova, R., Ayadi-Trabelsi, M., et al. (2015). Accelerated solvent extraction of carotenoids from: Tunisian kaki (Diospyros kaki L.), peach (Prunus persica L.) and apricot (Prunus armeniaca L.). Food Chem. 184, 131-139. doi: 10.1016/j.foodchem. 2015.03.072

Zagrobelny, M., Bak, S., and Møller, B. L. (2008). Cyanogenesis in plants and arthropods. Phytochemistry 69, 1457-1468. doi: 10.1016/j.phytochem.2008.02.019

Zhang, D., Yu, B., Bai, J., Qian, M., Shu, Q., Su, J., et al. (2012). Effects of high temperatures on UV-B/visible irradiation induced postharvest anthocyanin accumulation in 'Yunhongli No. 1' (Pyrus pyrifolia Nakai) pears. Sci. Hortic. 134, 53-59. doi: 10.1016/j.scienta.2011.10.025

Zhang, L., Zhang, Q., Li, W., Zhang, S., and Xi, W. (2019). Identification of key genes and regulators associated with carotenoid metabolism in apricot (Prunus armeniaca) fruit using weighted gene coexpression network analysis. BMC Genomics 20, 876. doi: 10.1186/s12864-019-6261-5

Zhao, Y., Wang, J., Ballevre, O., Luo, H., and Zhang, W. (2012). Antihypertensive effects and mechanisms of chlorogenic acids. Hypertension Res. 35, 370-374. doi: $10.1038 / \mathrm{hr} .2011 .195$

Zhao, X., Zhang, W., Yin, X., Su, M., Sun, C., Li, X., et al. (2015). Phenolic composition and antioxidant properties of different peach [Prunus persica (L.) Batsch] cultivars in China. Int. J. Mol. Sci. 16 (3), 5762-5778. doi: 10.3390/ ijms16035762

Zhao, Y., Dong, W., Wang, K., Zhang, B., Allan, A. C., Lin-Wang, K., et al. (2017). Differential Sensitivity of Fruit Pigmentation to Ultraviolet Light between Two Peach Cultivars. Front. Plant Sci. 8, 1552. doi: 10.3389/fpls.2017.01552

Zhou, Y., Zhou, H., Lin-Wang, K., Vimolmangkang, S., Espley, R. V., Wang, L., et al. (2014). Transcriptome analysis and transient transformation suggest an ancient duplicated MYB transcription factor as a candidate gene for leaf red coloration in peach. BMC Plant Biol. 14, 388. doi: 10.1186/s12870-0140388-y

Zhou, H., Lin-Wang, K., Liao, L., Gu, C., Lu, Z., Allan, A. C., et al. (2015a). Peach MYB7 activates transcription of the proanthocyanidin pathway gene encoding leucoanthocyanidin reductase, but not anthocyanidin reductase. Front. Plant Sci. 6, 908. doi: 10.3389/fpls.2015.00908

Zhou, H., Lin-Wang, K., Wang, H., Gu, C., Dare, A. P., Espley, R. V., et al. (2015b). Molecular genetics of blood-fleshed peach reveals activation of anthocyanin biosynthesis by NAC transcription factors. Plant J. 82, 105-121. doi: 10.1111/ tpj. 12792

Zhou, H., Peng, Q., Zhao, J., Owiti, A., Ren, F., Liao, L., et al. (2016). Multiple R2R3-MYB Transcription Factors Involved in the Regulation of Anthocyanin Accumulation in Peach Flower. Front. Plant Sci. 7:1557. doi: 10.3389/ fpls.2016.01557

Zhou, D., Li, R., Zhang, H., Chen, S., and Tu, K. (2020). Hot air and UV-C treatments promote anthocyanin accumulation in peach fruit through their regulations of sugars and organic acids. Food Chem. 309, 125726. doi: 10.1016/ j.foodchem. 2019.125726

Zhu, J. C., and Xiao, Z. B. (2019). Characterization of the key aroma compounds in peach by gas chromatography-olfactometry, quantitative measurements and sensory analysis. Eur. Food Res. Technol. 245, 129-1241.

Ziegler, J., and Facchini, P. J. (2008). Alkaloid Biosynthesis: Metabolism and Trafficking. Annu. Rev. Plant Biol. 59, 735-769. doi: 10.1146/annurev.arplant. 59.032607 .092730 
Ziliotto, F., Begheldo, M., Rasori, A., Bonghi, C., and Tonutti, P. (2008). Transcriptome profiling of ripening nectarine (Prunus persica L. Batsch) fruit treated with 1-MCP. J. Exp. Bot. 59, 2781-2791. doi: 10.1093/jxb/ern136

Conflict of Interest: The authors declare that the research was conducted in the absence of any commercial or financial relationships that could be construed as a potential conflict of interest.
Copyright (c) 2020 Lara, Bonghi, Famiani, Vizzotto, Walker and Drincovich. This is an open-access article distributed under the terms of the Creative Commons Attribution License (CC BY). The use, distribution or reproduction in other forums is permitted, provided the original author(s) and the copyright owner(s) are credited and that the original publication in this journal is cited, in accordance with accepted academic practice. No use, distribution or reproduction is permitted which does not comply with these terms. 